Check for updates

Cite this: J. Mater. Chem. B, 2020 8, 10487

Received 4th July 2020

Accepted 11th October 2020

DOI: $10.1039 / \mathrm{d} 0 \mathrm{tb} 01658$

rsc.li/materials-b

\section{Advanced biomedical applications based on emerging 3D cell culturing platforms}

\author{
Anheng Wang, (D) ${ }^{a}$ Leigh A. Madden (D) ${ }^{b}$ and Vesselin N. Paunov (D) *a
}

It is of great value to develop reliable in vitro models for cell biology and toxicology. However, ethical issues and the decreasing number of donors restrict the further use of traditional animal models in various fields, including the emerging fields of tissue engineering and regenerative medicine. The huge gap created by the restrictions in animal models has pushed the development of the increasingly recognized three-dimensional (3D) cell culture, which enables cells to closely simulate authentic cellular behaviour such as close cell-to-cell interactions and can achieve higher functionality. Furthermore, 3D cell culturing is superior to the traditional 2D cell culture, which has obvious limitations and cannot closely mimic the structure and architecture of tissues. In this study, we review several methods used to form 3D multicellular spheroids. The extracellular microenvironment of 3D spheroids plays a role in many aspects of biological sciences, including cell signalling, cell growth, cancer cell generation, and anti-cancer drugs. More recently, they have been explored as basic construction units for tissue and organ engineering. We review this field with a focus on the previous research in different areas using spheroid models, emphasizing aqueous two-phase system (ATPS)-based techniques. Multi-cellular spheroids have great potential in the study of biological systems and can closely mimic the in vivo environment. New technologies to form and analyse spheroids such as the aqueous twophase system and magnetic levitation are rapidly overcoming the technical limitations of spheroids and expanding their applications in tissue engineering and regenerative medicine.
${ }^{a}$ Department of Chemistry, University of Hull, Hull, HU6 7RX, UK.

E-mail:V.N.Paunov@hull.ac.uk; Tel: +44 1482465660

${ }^{b}$ Department of Biomedical Science, University of Hull, Hull HU6 7RX, UK

\section{Introduction}

\subsection{The spheroid model}

After the concept of the 3D cell spheroid model was introduced, various attempts have been made to simplify the generation

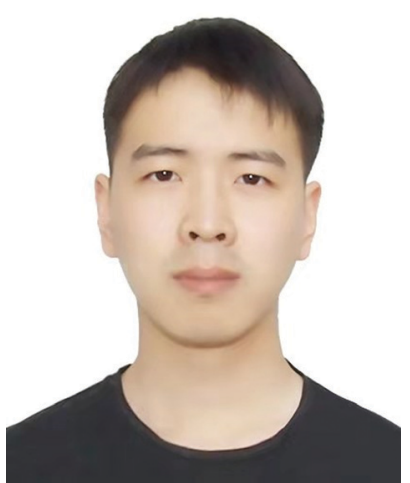

Anheng Wang
Mr AnHeng Wang obtained an MSc Degree in Chemistry from Shenyang Normal University (China) in 2019. Currently, he is a PhD student at the University of Hull under the supervision of Professor Vesselin Paunov and Dr Leigh Madden. His PhD studies involve $3 D$ cell culturing and tissue engineering. His research is focused on the applications of cell spheroids in regenerative medicine.

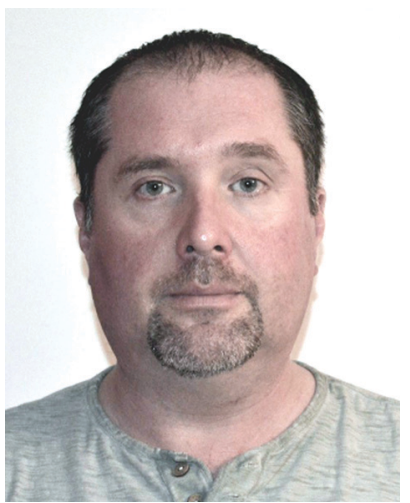

Leigh A. Madden
Dr Leigh A. Madden received a PhD from the University of Hull, UK in 1997. He then continued his work on biodegradable polymers for a further 2 years in a position funded by Monsanto Inc. After this he moved to the medical field at the Postgraduate Medical Institute at the University of Hull conducting research into a range of diseases, with a primary focus on cancer. Currently, working in the new School of Life Sciences at the University of Hull, his research interests include the investigation of cellular micro-vesicles in cancerrelated coagulation and the application of chemistry-derived technology such as microfluidics and bioimprinting in medical research. 
of spheroids. With the increasing yield and decreasing lab cost of spheroids, they have been increasingly employed in different fields including clinical trials, biomedical science, pharmacology, and personal disease care. The ultimate purpose of spheroids is tissue engineering and regenerative medicine applications. ${ }^{1,2}$ Compared to the traditional 2D cell culture, the condensed packed spheroids have the merits of better replicating the extracellular microenvironment, which are considered to be highly associated with cell growth and cell signalling. ${ }^{3,4}$ Since the knowledge on preparation methods, imaging, different assays and maintenance of spheroids has greatly improved, major attempts have been made to investigate the in vivo implantation of spheroids in various animal models, including rats and rabbits to study tissue regeneration. ${ }^{5}$ Cell spheroids, also known as multicellular spheroids (MCS), are the simplest in vitro model of solid cell clusters. Spheroids are generated due to the production of several key proteins including fibronectin and collagen to form intercellular adhesions and self-assemble into compact aggregates.

Generally, the progress achieved is based on a non-adherent surface or within a 3D matrix, which can conveniently produce spheroids with different sizes ranging from the micrometre to millimetre scale. ${ }^{6}$ Since spheroids grow to around $100 \mu \mathrm{m}$, their depth causes their different parts to experience non-uniform concentrations of soluble factors. The unavailability of oxygen deep inside spheroids results in a hypoxic core. Thus, to overcome this issue, there have been various attempts to vascularize the in vitro 3D spheroid model to maintain spheroids with a larger size. ${ }^{1}$ Additionally, spheroids offer the flexibility of incorporating different stromal components to accommodate studies on how physical interactions between cancer cells and tumour stroma and

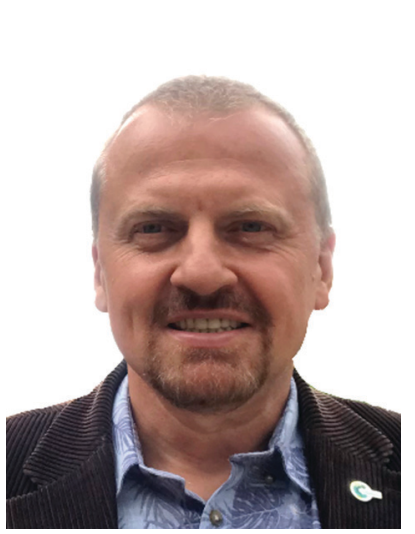

Prof. Vesselin N. Paunov received his PhD in Physical Chemistry in 1997 from the University of Sofia, Bulgaria. He worked as a visiting researcher at the Universities of Patras, Greece, and Erlangen, Germany and as a Postdoctoral Researcher at the University of Delaware, USA. In 2000 he took an academic post at the University of Hull, UK where he is currently a Professor of Physical Chemistry and Advanced Materials in the Department of Chemistry and Biochemistry. His present research interests include formulation science, microencapsulation, triggered release of actives, antimicrobial nanoparticles, colloid antibodies for cell shape recognition and selective targeting. His ongoing research is focused on antimicrobial nanoparticles, tissue engineering, whole cell bioimprinting techniques and bioimprint-cell interactions. To date, he has published over 170 research articles, which have received more than 8700 citations. intercellular signalling regulate tumour growth, angiogenesis, invasion, and drug resistance. ${ }^{7,8}$

Due to these advantageous features, there has been a major trend to utilize spheroids as surrogate tumour models in tissue engineering and regenerative medicine. However, after ten years of development, the field is still used empirically rather than theoretically. This is because the concept of spheroids precedes technology. Since the first bioprinters were used to produce spheroids, no major progress has been achieved in this area. All variants (inkjet, micro-extrusion and laser-assisted) are just modified versions of the prototype 3D printers. Thus, the stagnation of bioprinting technology has halted the development of spheroid technology. A scaffold-free and lab-friendly bioprinter with high throughput is the key the further development of spheroids. More importantly, scaffold-based techniques make it inherently difficult to boost the yield of spheroids, which consequently limit the application of spheroids to simple drug testing. Recently, spheroids have been shown to be suitable for use as individual blocks in tissue formation; however, at low yields, and thus a lack of bricks makes it hard to build a "wall".

\subsection{Purpose of this review}

A scaffold-free and lab-friendly bioprinter with high throughput was not available until the invention of the microneedle-based, non-scaffold-based 'Kenzan' bioprinter. ${ }^{9}$ This technique could fuse spheroids into cellular aggregates without any scaffold and synthesize their extracellular matrix directly. This breakthrough in bioprinting techniques can manipulate spheroids into the required architecture with great robustness. This novel technology opens wide opportunities for the bio-engineering of tissues and organs. Simultaneously, higher requirements especially the yield result in high standards for the manufacturing of spheroids. Recently, researchers have developed several scaffold-free techniques using spheroids for achieving a larger yield with controlled cell cluster sizes and properties.

Herein, we do not review all the techniques for spheroid culture. Impressive comprehensive reviews have been discussed by others. ${ }^{11,86,105}$ Instead, we focus on multicellular spheroids formed without a scaffold, especially recently developed aqueous two-phase system (ATPS)-based techniques, and further discuss the applications of high-throughput spheroids in order to widen the applicability of spheroids in biomedical research.

\section{Current methods to generate MCS}

Simple and high yield methods for generating MCS are a prerequisite for spheroid applications. Preventing cells from attaching to the culture ware substratum is the basic requirement for the generation of MCS. For a higher standard in the generation of spheroids, the production efficiency, MCS size uniformity, possible cellular damage, yield rate, efficiency, cytotoxicity, cell growth, efficiency and applicability should all be considered. There are several excellent review papers on the fabrication methods for spheroids. ${ }^{10-12}$ Thus, here we mainly discuss scaffold-free techniques, emphasizing ATPS- and magnetic 


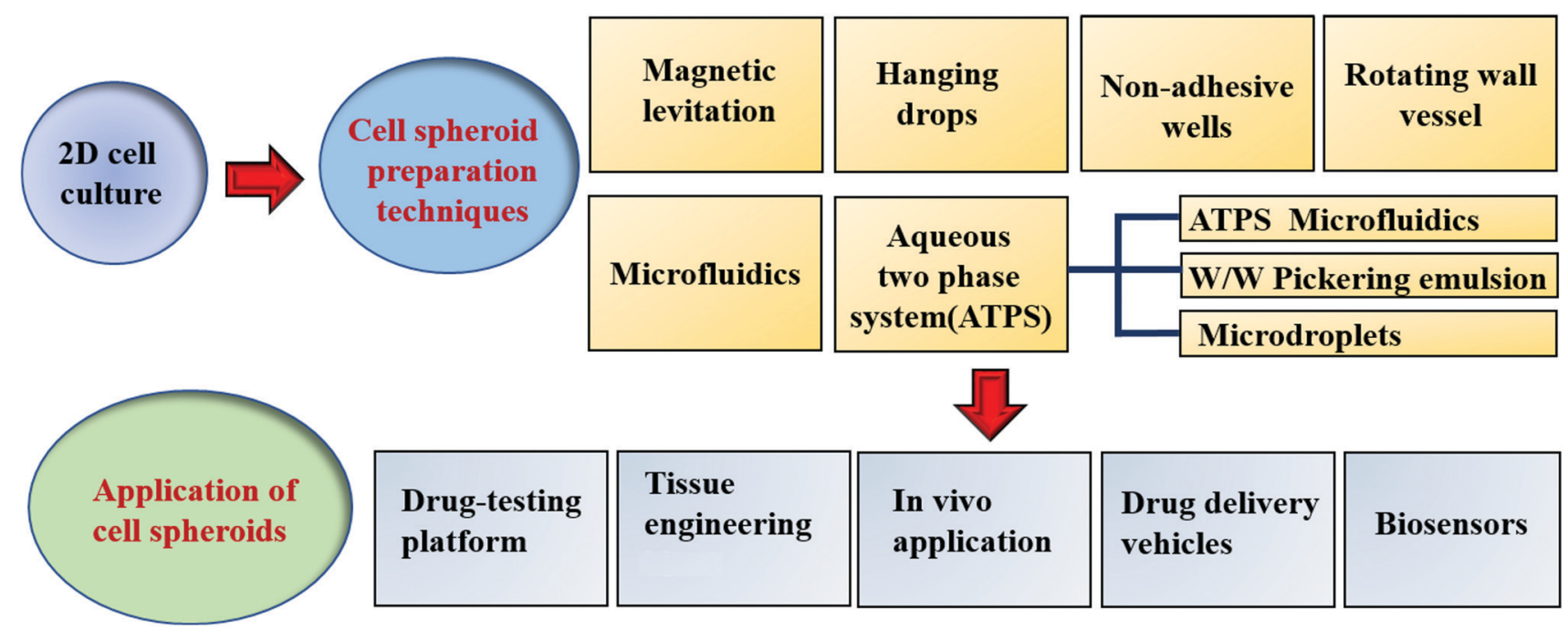

Scheme 1 Preparation techniques and various applications of cell spheroids.

Table 1 Current methods for the preparation of cell spheroids

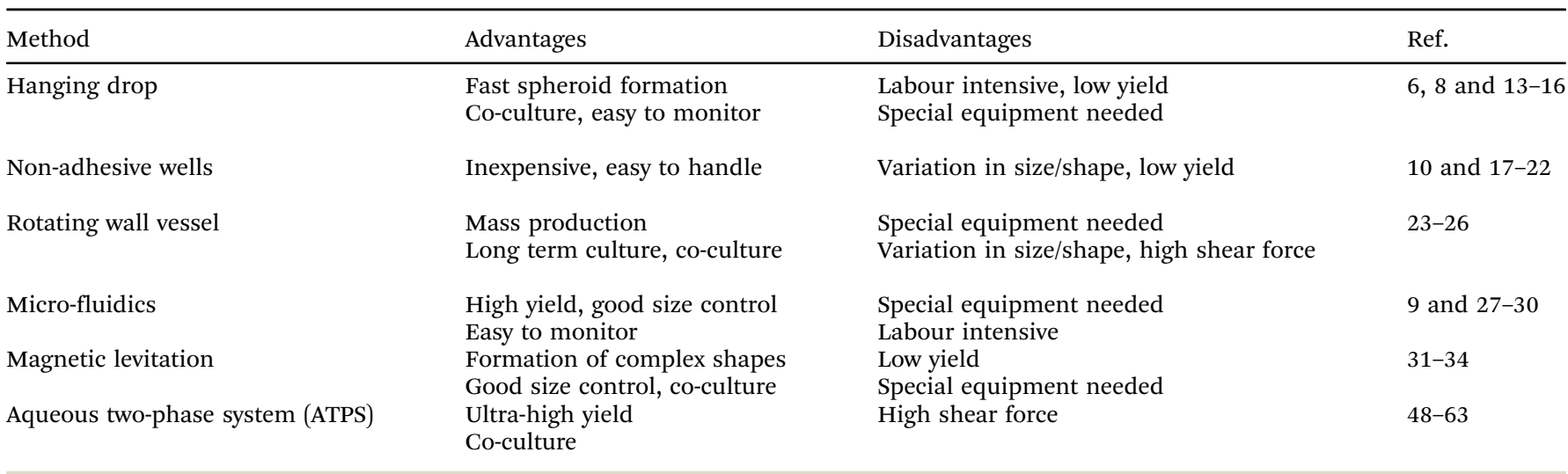

levitation-based techniques and their applications (see Scheme 1). Table 1 summarizes the current scaffold-free MCS generation techniques together with their advantages and shortcomings.

\subsection{The hanging drop method}

The hanging drop is the most commonly used method to generate spheroids. This method relies on gravity and upsidedown droplets to force cells into spheroids. ${ }^{13}$ During the formation of aggregates, a small number of cells are hung upside down on the cell culture plate. Due to surface tension, droplets remain attached to the cell culture plate and the cells are forced to aggregate into spheroids under the influence of gravity. Without a robotic system, this method is considered to be quite labour intensive. Cells gradually grow over several days to form large aggregates. ${ }^{6,14}$ The growth of spheroids can be easily monitored in the droplets. A variety of cell types have been proven to be able to form spheroids using this method including both Hep-G2 and HEK. ${ }^{8,15,16}$ Different cell types can be co-cultured or even tricultured in a droplet to form heterotypic spheroids. The convenience of observation to easily harvest the cell spheroids whenever they have grown to sufficient size and structure is an advantage.
Spheroid size and composition are mainly controlled by adjusting the initial cell density and growth time in each droplet. However, due to methodological limitations, the hanging drop method has difficulty producing large numbers of spheroids simultaneously. ${ }^{13}$ Another limitation of this method is the high demand for equipment.

\subsection{Non-adhesive wells}

The generally used Petri dishes and culture plates can only culture 2D cell plates. Specifically, they are treated, and a nonadhesive is formed, and then they are suitable for generating MCS. ${ }^{17-21}$ This protocol has been widely used for different types of spheroid culture. Culture ware can be easily made non-adhesive for cells by coating them with agarose thin films ${ }^{17}$ and hydrophobic polymers, including poly(2-hydroxyethyl methacrylate) (PHEMA) ${ }^{22}$ and poly- $N p$-vinylbenzyl-D-lactonamide. ${ }^{10}$ After the formation of the film, different types of cells can be gently seeded in the wells. In this simple culture method, the cultivation time and the number of initial cells are the main factors affecting the structure and size of the spheroids. ${ }^{10}$ This method possesses low requirements for laboratory conditions and can be performed in 
most labs. However, the spheroids generated by this method usually display broad size distributions due to the inaccuracy of the coated film. Consequently, the spheroids characteristics may not be well controlled.

\subsection{Rotating wall vessel}

The rotating wall vessel creates a microgravity environment, similar to an upgraded version of the hanging drop method. The environment can maintain cells in suspension and allow cells to firstly aggregate into spheroids upon slow rotation $\sim 15 \mathrm{rpm}^{23}$ As a globule begins to grow, its size and mass subsequently increase. After this point, the low speed is not capable of rotating the spheroids. Thus, the speed has to be gradually increased in the range of 15 and 25 (rpm). ${ }^{24-26}$ However, due to the complexity of this method, additional equipment is needed. Spheroids from a series of cells including mesenchymal stem cells and HUVEC have been formed using this method. Vascularized spheroids can be formed by the co-culture of cancer cells and endothelial cells. ${ }^{23-26}$ Stem cell culture is possible, and the conditions can be controlled by changing the medium, which is essential for controlled differentiation. This method produces aggregates in a low shear environment, which is basically harmless to most cells. However, the monitoring of the spheroids during culture is quite difficult due to the rotation; meanwhile, the low yield and variable size are due to the same reason.

\subsection{Microfluidic-based methods}

Microfluidics involves flowing cells through a series of microchannel networks into micro-chambers. The micro-chambers can be designed into different shapes to partition the cells and cause them to aggregate. ${ }^{27}$ It is worth mentioning that some microfluidic devices use a non-adhesive surface to form spheroids. ${ }^{106-108}$
This method has been proven to work for primary cells, cancer cell lines, and the co-culture of multiple cell types. ${ }^{9,16,19,27}$ The accuracy of microfluidic devices allow the production of precise size-controlled spheroids for high throughput analysis. Optional equipment such as biosensors and imaging systems can meet the needs of observation and testing. ${ }^{28}$ Additionally, the circulatory system can import fresh culture medium to control the soluble factors surrounding the spheroids. ${ }^{16,23}$ This method also shows high efficiency for drug testing and the co-culture of spheroids. ${ }^{13,27,29,30}$ The biggest merit of the microfluidic-based method is that it can accurately control the size of the formed cell spheroids, while having high yield, which can be easily altered by the device configuration. However, the capacity of the microfluidic method for the production of large quantities of cell spheroids required for tissue engineering is limited.

\subsection{Magnetic levitation}

Magnetic technology is used in various medical fields due to its biocompatibility. Magnetic levitation is based on bioinorganic hydrogels composed of bacteriophages (phages) plus magnetic iron oxide (MIO; $\mathrm{Fe}_{3} \mathrm{O}_{4}$, magnetite) and gold nanoparticles, which self-assemble into hydrogels and can potentially be adapted for high-throughput screening/high content screening ${ }^{31}$ (Fig. 1). Also, substances such as poly-L-lysine can also be used on particles to encourage cells to attach to the nanoparticles. Magnetic nanoparticles are treated to incorporate individual cells. ${ }^{32-34}$ Subsequently, the cells are forced to aggregate by changing the magnetic force via a magnet. The advantage of this technology is that it can control the size and form of spheroids by applying different magnetic forces and further induce cells to adhere together and generate dense tissue. ${ }^{31-33}$

However, the presence of magnetic particles can be concern for the application of the resulting cells.

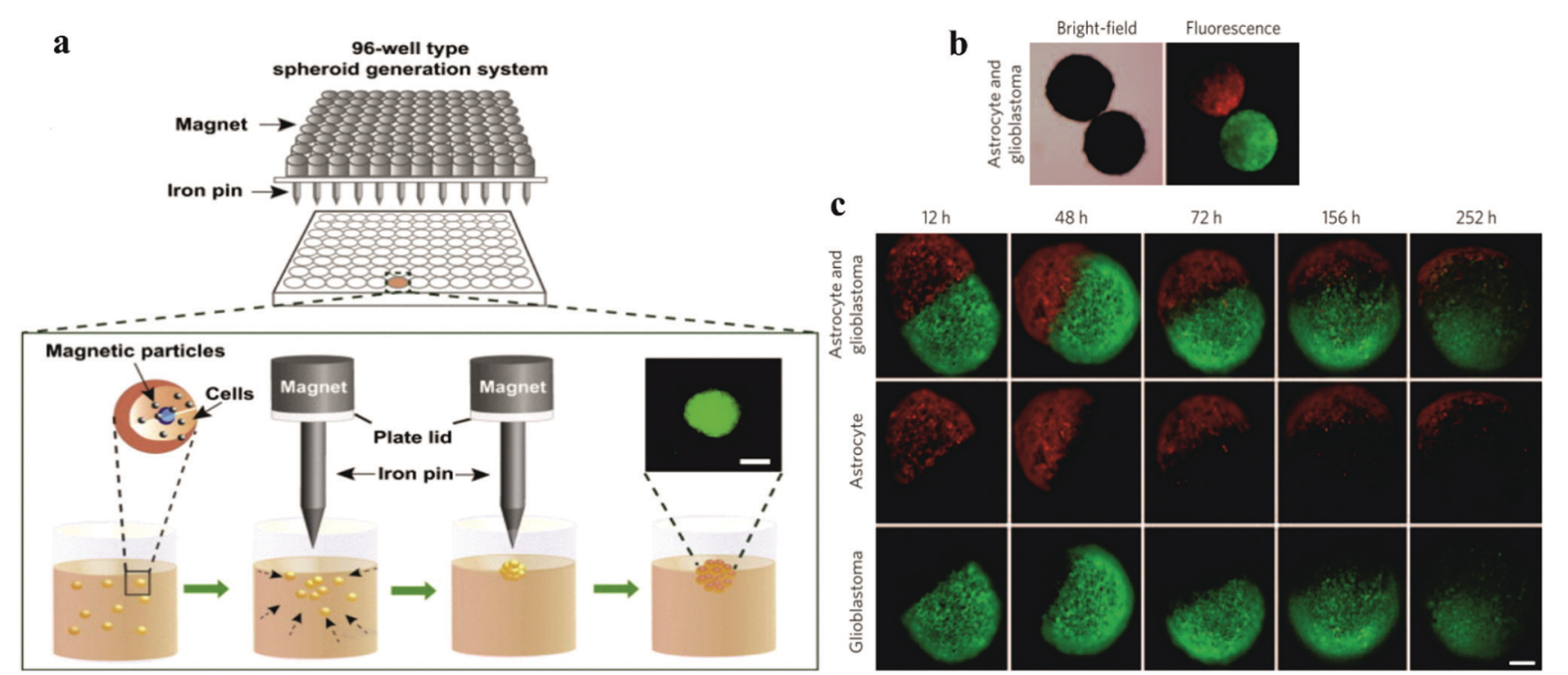

Fig. 1 (a) Schematic showing the spheroid generation platform using magnetic nanoparticles and iron pins. ${ }^{35}$ Reprinted with permission from ref. 35 ; Copyright 2013 Elsevier. (b) Magnetic bright-field and fluorescence images of human glioblastoma cells (green; GFP-expressing cells) and normal human astrocytes (red; mCherry-labelled) cultured separately and then magnetically guided together. (c) Confrontation between human glioblastoma cells and normal astrocytes monitored for different times. ${ }^{31}$ Reprinted with permission from ref. 31; Copyright 2015 Springer Nature. 


\subsection{Aqueous two-phase system (ATPS)}

Martinus Willem Beijerinck accidentally discovered the ATPS while mixing an aqueous solution of starch and gelatine in 1896. After decades, it was then applied for the first time by Per-Åke Albertsson. Since then, ATPS has gradually attracted attention and widely used in various industries. ${ }^{36-38}$ At high concentrations, this systems can be formed easily by shearing a variety of substances in water. ${ }^{39-41}$ Most of the research on ATPS has been focused on the separation of substances and purification products based on two incompatible polymer solutions and polymer-salt aqueous systems (e.g., phosphate, sulphate or citrate) with advantages over conventional extraction techniques. After a long period of development, some researchers have found that the biocompatibility of ATPS can allow it to be applied in the field of biomedical research. ${ }^{42,43}$ Its applications is based on its main component, water, since the organic solvent used in conventional extraction can cause serious damage to the viability of cells. ${ }^{42}$

In the biological application of ATPS, the most frequently mentioned system is formed using polyethene glycol (PEG) and dextran (DEX). At a certain concentration, the miscibility of the solution results in the formation of two phases. High concentrations of polymers and salt solutions are also commonly used in biaqueous systems, but they are obviously not biocompatible. In the DEX-PEO system, because of the steric exclusion between the two molecules, polymers start to separate into two different phases. The phase diagram is shown in Fig. 2, which mainly shows the properties of ATPS under certain conditions. ATPS systems may behave entirely different at different temperature and $\mathrm{pH}$. The phase diagram shows information such as at what concentration are the two phases capable of producing ATPS. ${ }^{43,45}$ ATPS can also be used to generate water-water emulsions, and phase transitions occur when the concentration difference between the two phases is too large. A binodal curve (TCB) divides the region of the concentration of the two phases.

2.6.1 Cell partitioning in ATPS. One of the main advantages of using ATPS in generating cell spheroids is the spontaneous partition of cells. ${ }^{44}$ Thus far, only a few studies have been conducted about the cell partitioning in the ATPS. ${ }^{46,47}$ There is no good comprehensive theory on an ATPS system containing cells. The work done by Atefi and co-workers demonstrated that the interfacial tension varies at different polymer concentrations of the two immiscible phases, which will influence the partition behaviour of cells, e.g. increasing the interfacial tension will cause cell accumulation at the interface (Fig. 2b-d). ${ }^{44}$

Iqbal et al. showed that the partition behaviour is determined by electrochemical, hydrophobicity, bio-specific affinity, and molecular weight, and it is conformation dependent. ${ }^{114}$ Increasing the interfacial tension reduces the resistance of cell movement and pushes them to the interface. In the formation of spheroids in ATPS, partition behaviour is a prerequisite. Due to the influence of gravity and surface properties of different cell types, the partition behaviour may vary.

\subsubsection{ATPS-based techniques to generate cell spheroids}

2.6.2.1 Microfluidic devices. By using microfluidic devices, the size of droplets can be controlled to shrink, burst or grow. ${ }^{48,49}$ Based on this control, several microfluidic devices have been optimized to use aqueous two-phase systems to

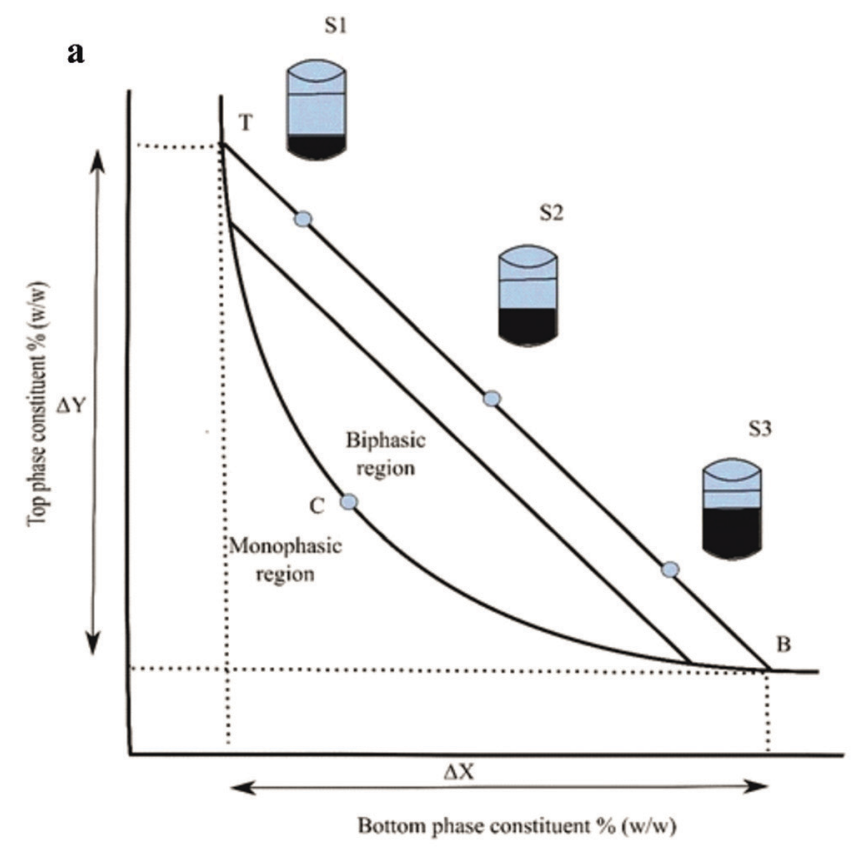

b

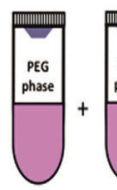

c
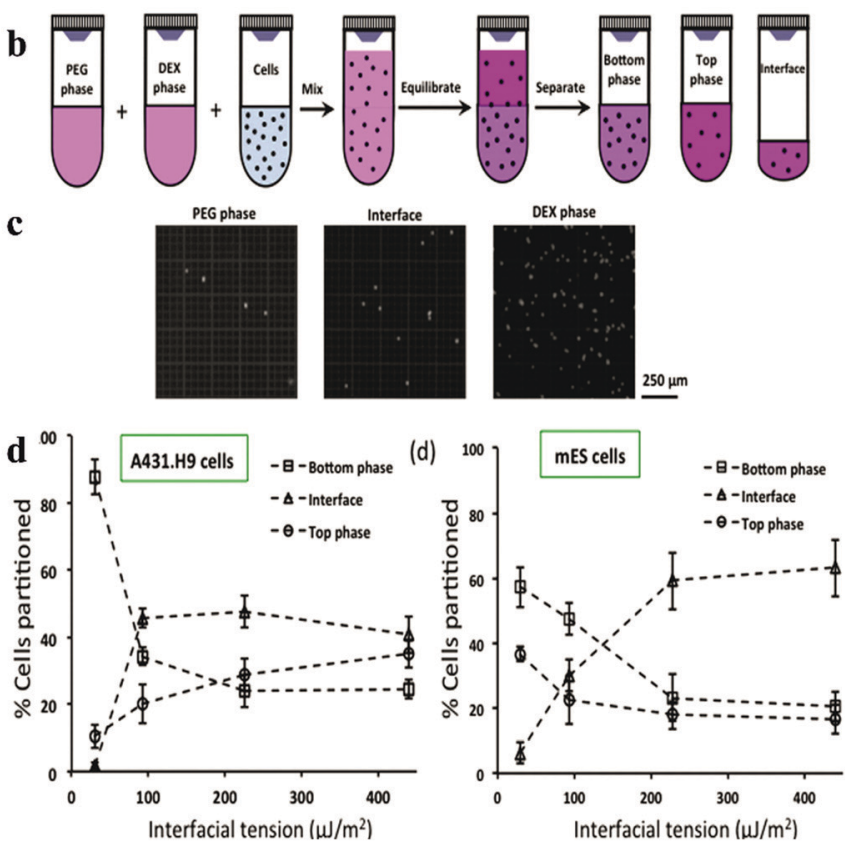

Fig. 2 (a) Schematic representation of the phase diagram. Concentrations above the binodal curve (TCB) form aqueous two-phase system clashes. ${ }^{41}$ (b) Schematic of cell partition experiments with aqueous two-phase systems. (c) Images of A431.H9 cells recovered from the top phase, interface, and bottom phase of the 5.0\% PEG-6.4\% DEX two-phase system and loaded on a hemo-cytometer counting. (d) Percentage of A431.H9 cells partitioned to each of the two bulk phases and their interface in four two-phase systems vs interfacial tension. ${ }^{44}$ Reprinted with permission from ref. 44 . Copyright 2015 American Chemical Society. 
generate spheroids. ${ }^{50-53}$ This approach is based on the use of a polymeric ATPS (DEX/PEG) to confine the cells within a nanolitre-volume aqueous drop immersed within a second, immersion aqueous phase in close proximity, and cells aggregate to spontaneously form a spheroid. The commonly used bioavailable ATPS is polyethene (PE) and dextran (DEX) due to the strong partition of cells to dextran in this system. An ATPS consisting of DEX and PEG was reported for the preparation of a cell-laden microgel using microfluidic devices, which involved a periodically changing injection force. ${ }^{50,52}$ The microfluidic devices will overcome the issue of low interfacial tension between the two phases. The microfluidic device chamber can pump out fluids with different injection conditions, which can control the size of droplets. Recently, Tomasi et al. describe a microfluidic droplet by combining microfluidic devices and an imaging system. This data-driven approach allowed the heterotopic 3D cell culturing behaviour to be monitored and linked single-cell measurements with population measurements. ${ }^{100}$

This platform yielded time-resolved, single-cell data, revealing a dynamic response regulated at the spheroid level. This was achieved by introducing a new asymmetric design for the anchors, which led to a qualitative transformation in the functionality of the microfluidic approach for a range of biological applications, including tissue engineering, models of immuno-therapies, and understanding host-pathogen interactions. The combination of precise control of single spheroids and high-density spheroids within this chip enabled quantitative observations of the dynamics of drug imposing to tumour spheroids model.

Another recent attractive work on microfluidic devices was introduced by Cristaldi et al., which could gather crucial information about cell spheroids, such as density, size, and weight. ${ }^{101}$

This technique is based on the detection of the terminal velocity of a free-falling sample in a specifically conceived analysis flow-channel. The device was proven to be capable of measuring cell spheroids with a size ranging from 20 to $200 \mu \mathrm{m}$ in diameter. To achieve this, the crosslinking reagents horseradish peroxidase (HRP) and $\mathrm{H}_{2} \mathrm{O}_{2}$ were firstly added to the DEX and PEO phase, respectively. Then the suspension was mixed without disturbing the ATPS system (Fig. 3a and b). Due to the resistance of the ATPS, cells were encapsulated in the microgel and maintained high viability and proliferation rates. Low concentrations of gelatine derivatives could be incorporated
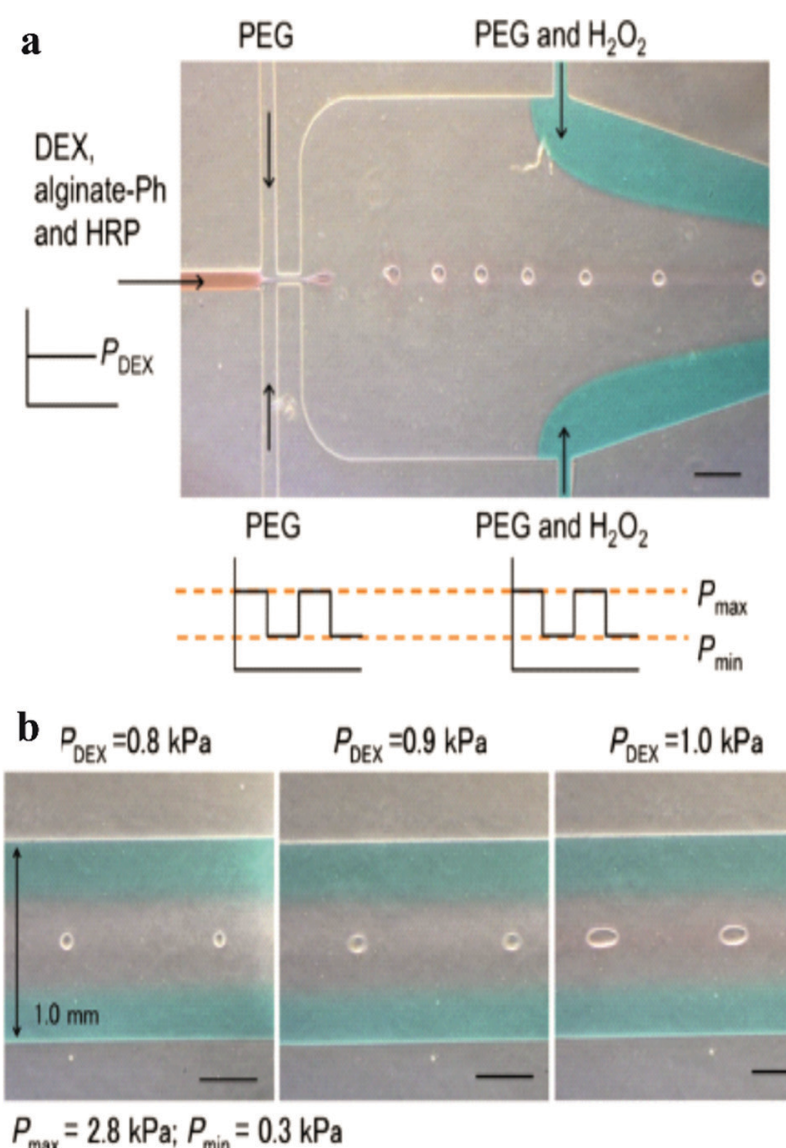
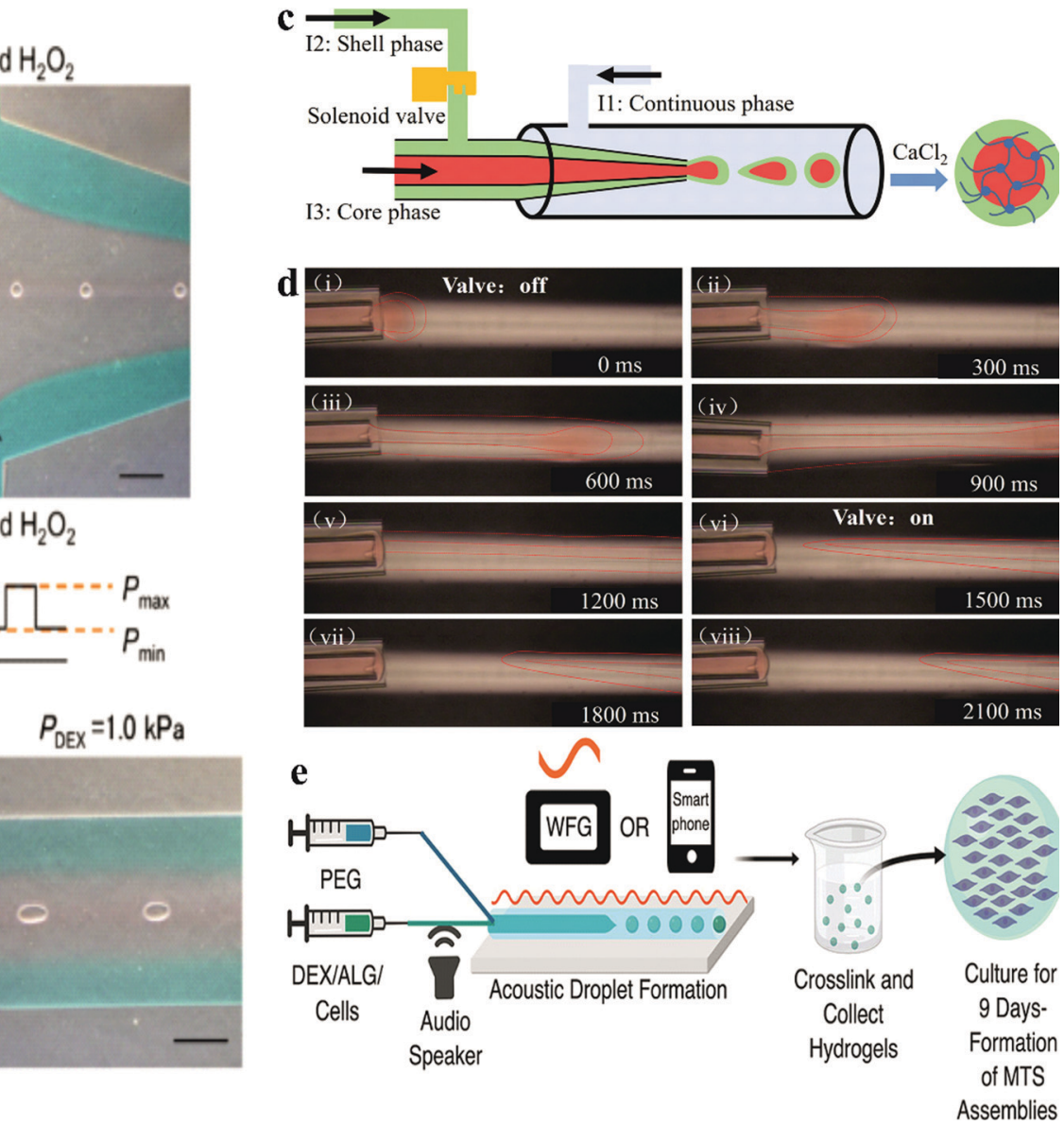

Fig. 3 (a) Production of microgel using DEX/PEG-based ATPS in microfluidic devices. ${ }^{50}$ Reprinted with permission from ref. 50 . Copyright 2017 Springer Nature. (b) Morphology of pre-gelated droplets passing through the narrowest channels in the downstream of the microfluidic device. (c) Schematic of the all-aqueous-phase microfluidic system for the fabrication of core-shell capsules. (d) Actual fabrication process of core-shell capsules with the help of a solenoid valve. ${ }^{54}$ Reprinted with permission from ref. 54. Copyright 2019 American Chemical Society. (e) Acoustic-fluidic device workflow for forming spherical hydrogels with encapsulated cells. ${ }^{52}$ Reprinted with permission from ref. 52. Copyright 2019 American Chemical Society. 
into the microgel, which promoted the cell adhesion properties of the microgel. Another microfluidic device based on all aqueous phases was designed by creating a shell-core structure. By encapsulating cells in the core phase, the shell phase was gelated to maintain the structure and induce the formation of spheroids (Fig. 3c and d).

Recently, De Lora et al. designed an original microfluidic device connected to smart devices. The electrical signals were driven by an amplified output of a waveform generator or even a smartphone, which provided acoustic modulation to generate an ATPS into multicellular tumour spheroid (MTS) template droplets (Fig. 3e). ${ }^{52}$ This method is the first microfluidic device that could be artificially controlled by a smart phone. It uses handy acoustic components, which are basically achievable in most labs.

2.6.2.2 Microdroplet method. The microdroplet method mainly utilizes gravity and cell partition behaviour in the ATPS, driving cells to accumulate at the apex and increase the cell/cell contact. $^{55-57}$ The alteration of the buoyancy force effect by altering the concentration of the two phases helps cells accumulate at the apex. Most of the cells would be trapped at the interface at the DEX drop meniscus after $4 \mathrm{~h}$ of culture in the system. At this stage, the gravity and surface tension from the interface are competing with the cells, which confine the cells at the interface due to the resultant force. DEX is a polysaccharide, which can attract more cells than the PEG phase, and thus a contact angle forms between the two phases. ${ }^{44,47}$ Different cells and different concentrations of the two phases change the contact angle, similar to the oil/water emulsion system. The formation of this contact angle exerts surface forces in a tangential direction to the contact point. Therefore, the main forces can be simplified as a free body diagram. As a result of this force interaction, a cell trapped at the interface moves along the phase interface until it reaches the apex of the DEX drop meniscus, where the forces are balanced (Fig. 4e). One to two days after pattern formation, most of the cells will gather at the apex of the DEX drop and form a tight cell spheroid or loose cell aggregate, depending on the cell characteristics. By changing the DEX/PEO phase concentration, the density of the two phases can easily be adjusted, thus making this method technically suitable for different types of cells. However, several cells such as HepG2, which prefer to form aggregates than spheroids, were shown to not be suitable for this method, highlighting the need to carefully identify and select cells for the formation of spheroids. However, this method can allow the growth of spheroids to be easily monitored. More importantly, the cell density and size of the spheroids can be easily controlled (Fig. 4a-d). With over 9 days culture, the spheroids grew to a diameter of $400 \mu \mathrm{m}$. Moreover, the functionality of these spheroids such as RNA expression dramatically improved compared to the monolayer culture (Fig. 5).

Another ATPS droplet-based method is carried out by pipetting DEX droplets containing cells directly into the PEG phase. The cells are automatically confined in the DEX droplets and form spheroids within $24 \mathrm{~h}$ (Fig. 5a-d). This method allows easy control of the spheroid density, and thus the size of the spheroids can be manipulated. Also, monitoring and various testing in this platform are convenient due to the ATPS system.
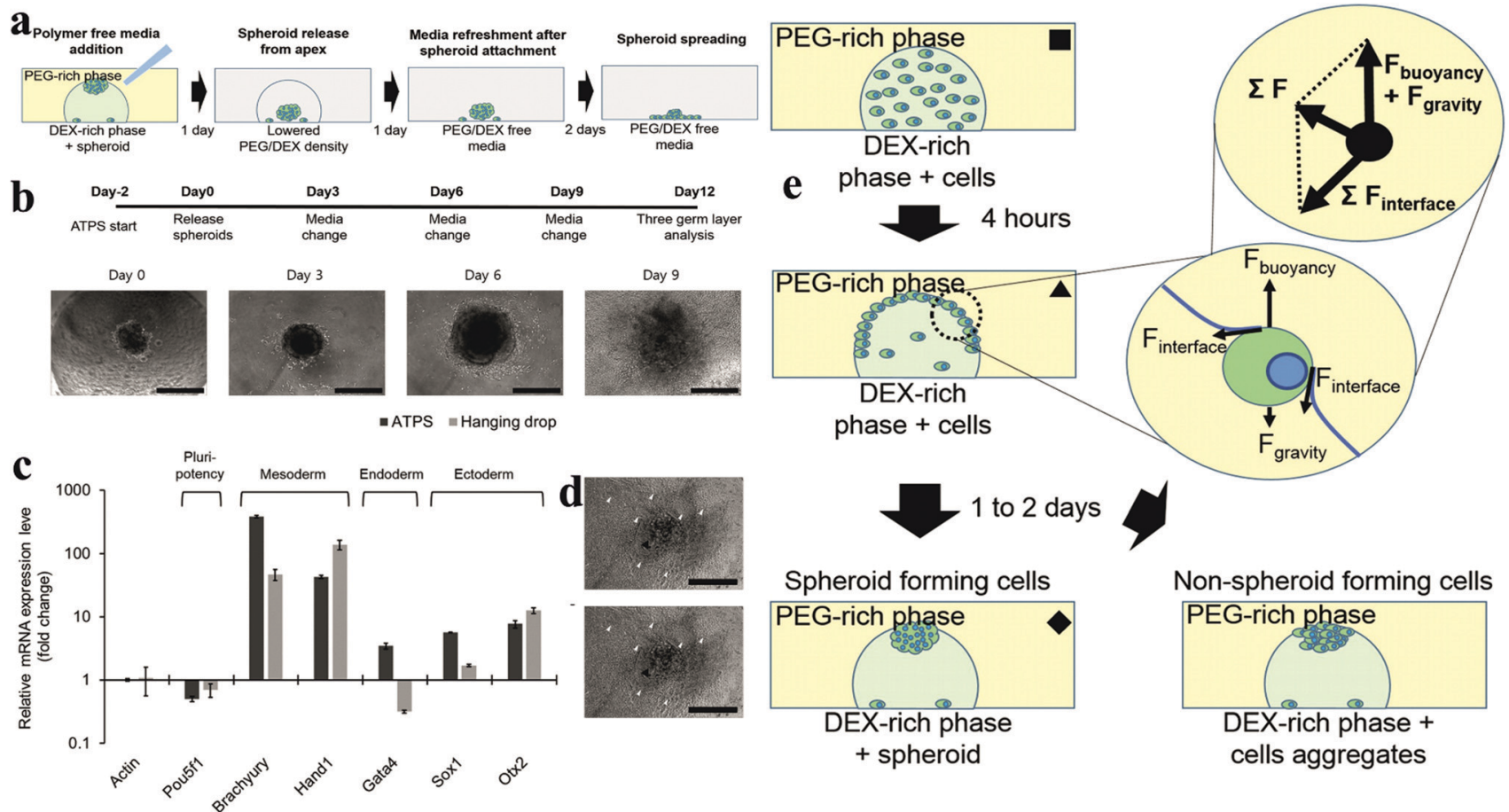

Non-spheroid forming cells PEG-rich phase

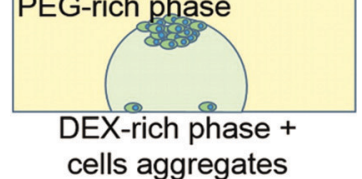

Fig. 4 (a) Adding PEG/DEX-free fresh medium decreases the density of the DEX-in-PEG ATPS pattern; therefore the floating spheroids settle. (b) Embryoid body (EB) formation and cardiac differentiation using DEX-in-PEG ATPS pattern. (c) qPCR analysis of representative three germ layer lineage markers. (d) Representative images of day 12 EBs. (e) Schematic model of ATPS spheroid formation. ${ }^{55}$ 

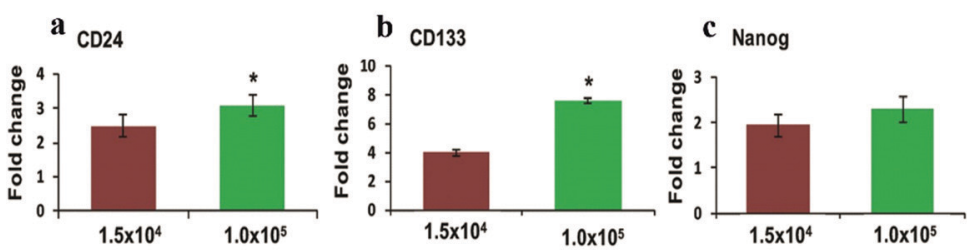

f

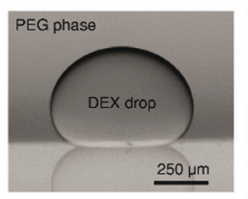

g

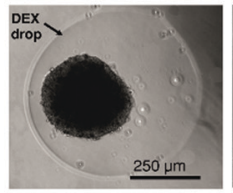

h

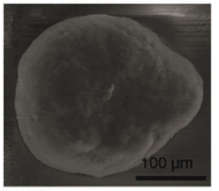

doechst
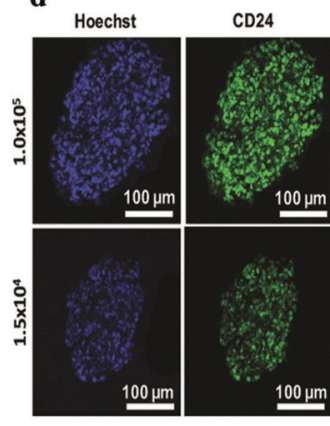

e Hoechst
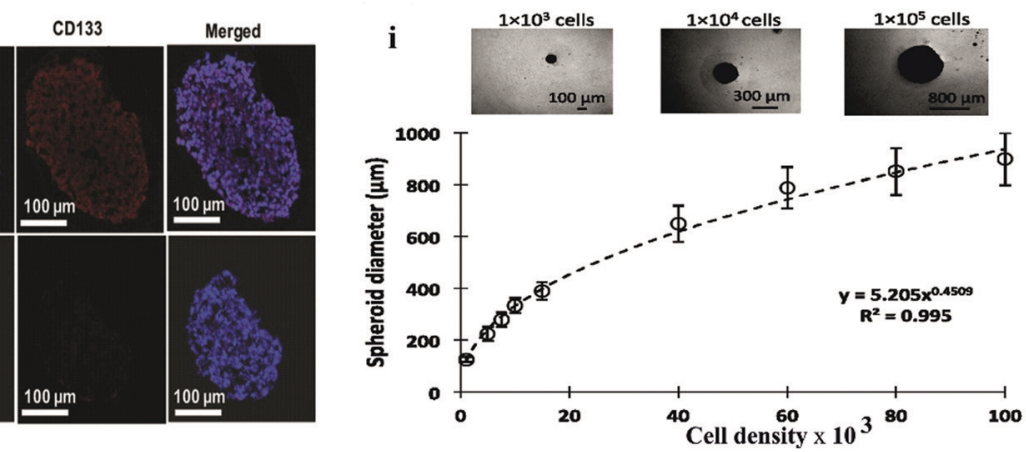

Fig. 5 q-PCR analysis of expression of (a) CD24, (b) CD133, and (c) Nanog in ATPS spheroids of MDA-MB-157 cells normalized against mRNA levels of a monolayer of cells. Largest cryosections of $1.5 \times 10^{4}$ and $1.0 \times 10^{5}$ cell density spheroids immune-stained for cancer stem cell markers. (d) CD24 (green) and (e) CD133 (red). ${ }^{56}$ Reproduced from ref. 58 with permission. Copyright 2016 John Wiley and Sons. (f) Side view of a DEX phase drop in the immersion PEG phase formed on a glass surface using equilibrated phases from an ATPS with initial composition of $6.4 \%$ (w/w) DEX and 5\% (w/w) PEG. (g) Top-view of A431.H9 skin cancer cell spheroid formed with a cell density of $1 \times 10^{4}$ cells at $24 \mathrm{~h}$. (h) Scanning electron microscopy (SEM) image of A431.H9 cells after one week of incubation. (i) Spheroids generated using a wide range of cell densities. ${ }^{57}$ Reproduced from ref. 56 with permission. Copyright 2014 John Wiley and Sons.

2.6.2.3 Water-in-water Pickering emulsions. Further research based on ATPS is the water-in-water (w/w) Pickering emulsion (Fig. 6). The w/w emulsion is another ATPS system, which generally consists of two immiscible aqueous phases and one stabilizer, e.g., protein particles. ${ }^{59-61}$ The emulsion is generated by gentle pump using needles to decrease the damage to cells. This technique initially confines the cells within emulsion droplets and then increases the concentration of the constant phase to impose osmotic pressure to fabricate spheroids within a very short time. ${ }^{62,63}$ This results in the encapsulation of the cells in the DEX emulsion drops due to the higher affinity of the cells to the DEX phase, as mentioned above. Cell-cell interactions are strongly promoted with the emulsion droplets, which assists the formation of $3 \mathrm{D}$ cell clusters, termed clusteroids. The collected clusteroids were put into an alginate gel to mimic real tissue generation. The results showed that the area and albumin linked to cell proliferation were reinforced compared to $2 \mathrm{D}$ monolayer culture. This methodology can potentially extend the w/w emulsion platform to tissue generation and drug tests. This technique allows a high yield of cell clusters without harming the viability of cells. However, only limited types of cells were proved to work in this technique and the detailed characteristics of the
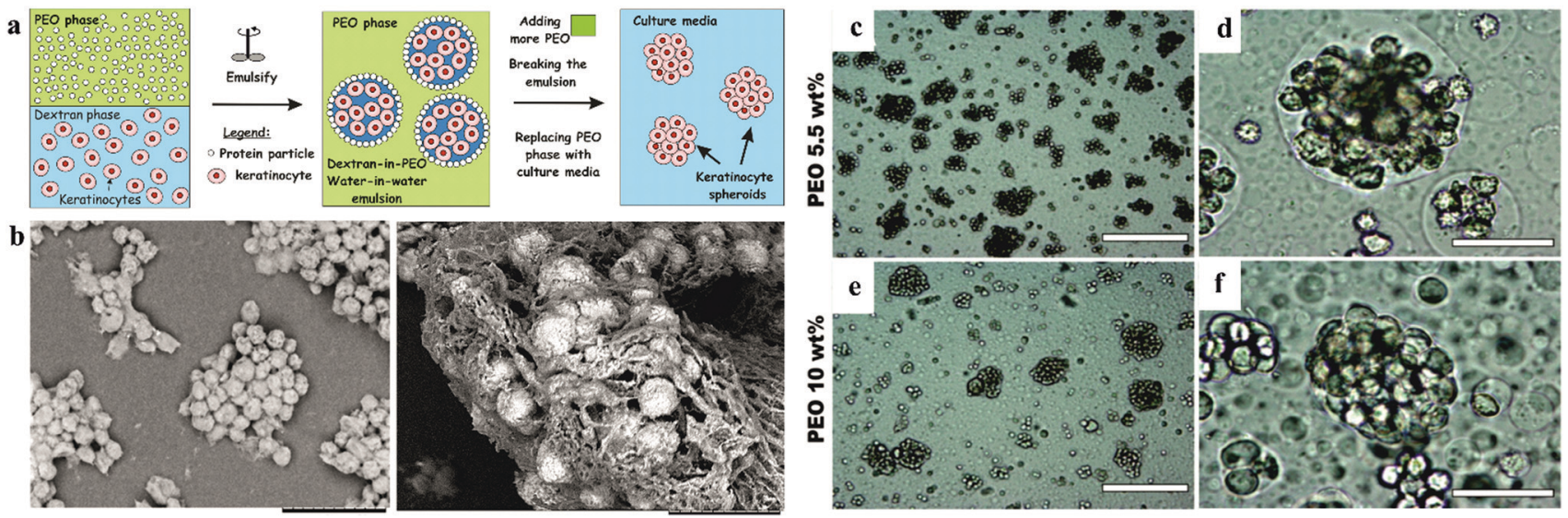

Fig. 6 Schematic model of spheroid formation in water-in-water Pickering emulsion. (a) Schematic of high-throughput method for the preparation of keratinocyte cell spheroids. (b) SEM images of a sample of HaCaT cell clusteroids after being removed from the medium. ${ }^{63}$ Optical microscopy images of (c-e) HaCaT cell droplets (5.5 wt\% PEO/5.5 wt\% Dextran) and (f-h) HaCaT cell clusteroids (10 wt\% PEO/5.5 wt\% Dextran) stabilized by 2 wt\% WP particles. Here the cell and DEX volume fraction were, $\phi_{\mathrm{HaCaT}}=0.15$ and $\phi_{\mathrm{DEX}}=0.25$, respectively. 
formed spheroids such as RNA expression, protein, enzyme need to be further explored.

2.6.2.4 New trends of using ATPS in spheroid application. Teixeira et $a l .{ }^{109}$ and Pereira et al. ${ }^{110}$ compared and discussed novel ATPS-based pattern bioprinting techniques, emphasizing their potential for three major aspects of (i) cell analysis, (ii) cell assembly and cell co-culture, and (iii) bacterial co-culture system.

Among these applications, the most attractive two are spheroid cultivation and 3D bioprinting. Tavana developed a polymeric ATPS system that can be used for the high-throughput fabrication ${ }^{111}$ of tumour spheroids at the microscale. Similar to the ATPS microdroplet assay, the cells are confined within droplets in the DEX phase, which is the bottom phase due to its higher density. This approach allows more cell-cell interactions, which will help spheroid formation. However, the major problem of the ATPS printing system is that it requires special equipment. Furthermore, the laborious processes of this equipment is time consuming. Accordingly, another ATPS-based system implementing a robotic system of a 384-microwell plate overcame this issue. ${ }^{111,112}$ Another example of a microtissue strategy using ATPS includes the use of ATPS to print cellcontaining contractile collagen microdroplets. ${ }^{113}$

The incorporation of robotic devices in ATPS-based techniques for $3 \mathrm{D}$ cell cultivation is another hot topic. Robotic devices can further improve the stability and productivity in drug screening using in vitro cell models. ${ }^{53}$ Another promising application of APTS to generate spheroid was reported by Celik et al., where generally, they embedded significant amounts of spheroids in alginate gel, which allowed the formation of skin-like tissue. ${ }^{63}$ These examples set the scene for the following research on the utilization of ATPS in the biomaterial field.

\section{Co-culture spheroids}

After spheroids grow to over $200 \mu \mathrm{m}$, a necrotic core may form because the outer layer of cells hinders nutrient and oxygen penetration into their core. Moreover, single-cell spheroid systems are rather limited in simulating the in vivo environment. Consequently, co-culture or tri-culture assays have been developed to promote the reliability of spheroid models. Co-culture has been widely accepted as a successful strategy to boost the production of genes and proteins in spheroids in vitro in tissue engineering. ${ }^{15,27,51,64-66}$ The results of the co-culture are mainly determined by the types of cells and the patterns of the co-culture. For example, different cells including endothelial cells (ECs), human adult keratinocytes (HaCaT), and mesenchymal stem cells have been co-cultured with hepatocytes, ${ }^{5,66-71}$ which either increased the liver-specific functionality such as albumin production or constructed angiogenesis tissue. In hepatic coculture/tri-culture spheroids, the hepatocytes are: (i) pre-mixed with another type of cells to allow cell self-sorting in the obtained spheroids. (ii) Culture two/three types of cell spheroids separately and arrange them in a plate-like or Janus-like structure with an EC layer or spheres. The ECs will potentiate the growth of the spheroids under limited oxygen delivery due to vascularization. ${ }^{72}$ Therefore, ECs are widely thought to be ideal cells for co-culture with the majority of cell types to prevent the formation of a necrotic core. The co-culture models enable direct cellular communication via gap junctions and paracrine mechanisms like liver tissue. ${ }^{102,103}$ Actual the cell microenvironment not only involves the metabolism of a single cell and its metastatic potential, it is usually composed of several types of cells and a scaffold structure to help the growth of cells. The co-culture or even tri-culture system can boost the complexity and reliability of spheroid models to achieve higher accuracy in drug testing and transplantation.

\section{Utilization of spheroids}

\subsection{Drug testing platform for regenerative medicine}

Tumour globules have been used as models to simulate tumour complexity in vitro. ${ }^{69,73}$

Mixed spheroids of mesenchymal stem cells and cancer cells have been used to study tumour-mesenchymal cell interactions. The stem cells provide co-cultured spheroids with enhanced functionality in protein, RNA and production in vitro. ${ }^{74}$ Hepatic cancer cells co-cultured with fibroblasts exhibit an invasive phenotype, forming tissues similar to primary hepatic cancer tissues in terms of protein expression in cancer cells. ${ }^{67,69} \mathrm{~A}$ three-dimensional tumour-endothelial model was used to measure the angiogenic and metastatic potential of tumour cells. The vascularized structure of the spheroids did not increase the drug penetration, but the tumour cells were more resistant to chemotherapy and radiotherapy. ${ }^{75,76}$

This thick structure compared to the cell sheet strongly blocked the drug penetration, including the antibodies and enzymes. ${ }^{36,77}$ This indicates the tumour-like structure of spheroids with different cell phenotypes, different proliferation rates and even different gene expression in different parts of the rather huge spheroids. Thus, the drug penetrability of spheroids will be an attractive research topic in the following decade. Tumour spheroids have been used to measure the three-dimensional penetrability of anthracyclines using fluorescence or autoradiography of radio-labelled drugs such as doxorubicin. ${ }^{104}$

Personalized medicine has also become an attractive topic since this approach will help increase the lifespan of patients. Accordingly, some patient-derived spheroids have been established and well-characterized. Individual cellular information on spheroids will be stored in a "biobank". This information can comprise the entire phenotype of tumor spheroids, and more importantly, the efficiency of various drugs on the patient-derived spheroid model will be recorded for future therapeutic options. ${ }^{115-117}$

\subsection{Tissue engineering blocks}

Tissue engineering involves the use of large numbers of cells to simulate organs or tissues in vitro, ultimately transplanting them into the body of a patient. However, the ideal is plump, but the reality is bony. The major drawback of tissue engineering is the low availability of a high density of living cells, for 
example the mono-spheroid diameter is limited to $200-400 \mu \mathrm{m}$ due to the restriction of oxygen and nutrients. Thus, to overcome the limitation of the size of spheroids, endothelial cells are widely used to vascularize cell spheroids to develop a capillary-like network. ${ }^{8,66,78-80}$

The applicable endothelialized spheroids used in clinical trials are all relatively thin tissues $(<2 \mathrm{~mm})$, where the transport of oxygen and nutrients occurs by simple diffusion. These 'endothelialized' spheroids can be further fused to form a larger tissue, which can integrate with the host vascular system after implantation. ${ }^{68,81-83}$ Before being implanted, the prevascularization step is crucial. $^{20,84-86}$ The emerging field of bioprinting and bio-fabrication is seeking larger clusters of cells to replace traditional cells to try and fabricate organs in vitro. Bio-printers, such as inkjet printing and other roboticbased devices, have been used to print tissue using extracellular matrix (ECM) with various structures including cell rings and cell sheets. ${ }^{9,78}$ Magnetic levitation is an attractive method for spheroid culture since the magnetic field can easily manipulate the shape of spheroids (Fig. 7a-e). Magnetic spheroids can be easily modulated into different shapes. ${ }^{31,32,85,87}$ Another emerging technique, ATPS-based generation of spheroids, has also been demonstrated to be an excellent source for direct-bioprinting. The bioavailability of ATPS makes it quite achievable to utilize this system as a type of bio-ink for the fast-formation of tissue constructs (Fig. 7f). ${ }^{35,58,88,89}$

Another promising application of spheroids in tissue engineering is adapting stem cell spheroids for bone generation. In the human body, compact bone is composed of repeating microscale units called osteons instead of monolayer cells. These cells are hierarchically organized into a large bone structure similar to that of spheroids. ${ }^{118-120}$ Accordingly, 3D spheroid cell cultures can mimic key aspects of native bone cellular microenvironments and hierarchical organization, and thus have attracted a great deal of attention from researchers in bone tissue engineering. Hoefner et al. developed human adipose-derived mesenchymal stromal/stem cell spheroids possessing high adipogenic capacity. The adipose-derived mesenchymal stromal/stem cells exhibited enhanced adipogenic capacity and generates adipose-like microtissues, which may be a promising cell delivery strategy for adipose tissue engineering approaches. ${ }^{121,122}$ Stem cells can also differentiate in to many cell types. After stem cells were made into spheroids, growth factors were added to allow the desired aspect of differentiation. This unique property makes them functional building blocks for tissue engineering with great potential.

\subsection{In vivo applications}

Owing to their many excellent features, spheroids are increasingly being employed in a wide range of pathological, metabolic studies in the biomedical area with the ultimate purpose of implantation (Fig. 8). Cell size is counted when transplanting tissue. Compared to $2 \mathrm{D}$ cells, spheroids can be individually implanted into mammalian animals. Also, since the knowledge about the preparation and maintenance of spheroids has improved, there has been a plethora of translational experiments investigating the in vivo implantation of spheroids into various animal models and tissue generation.
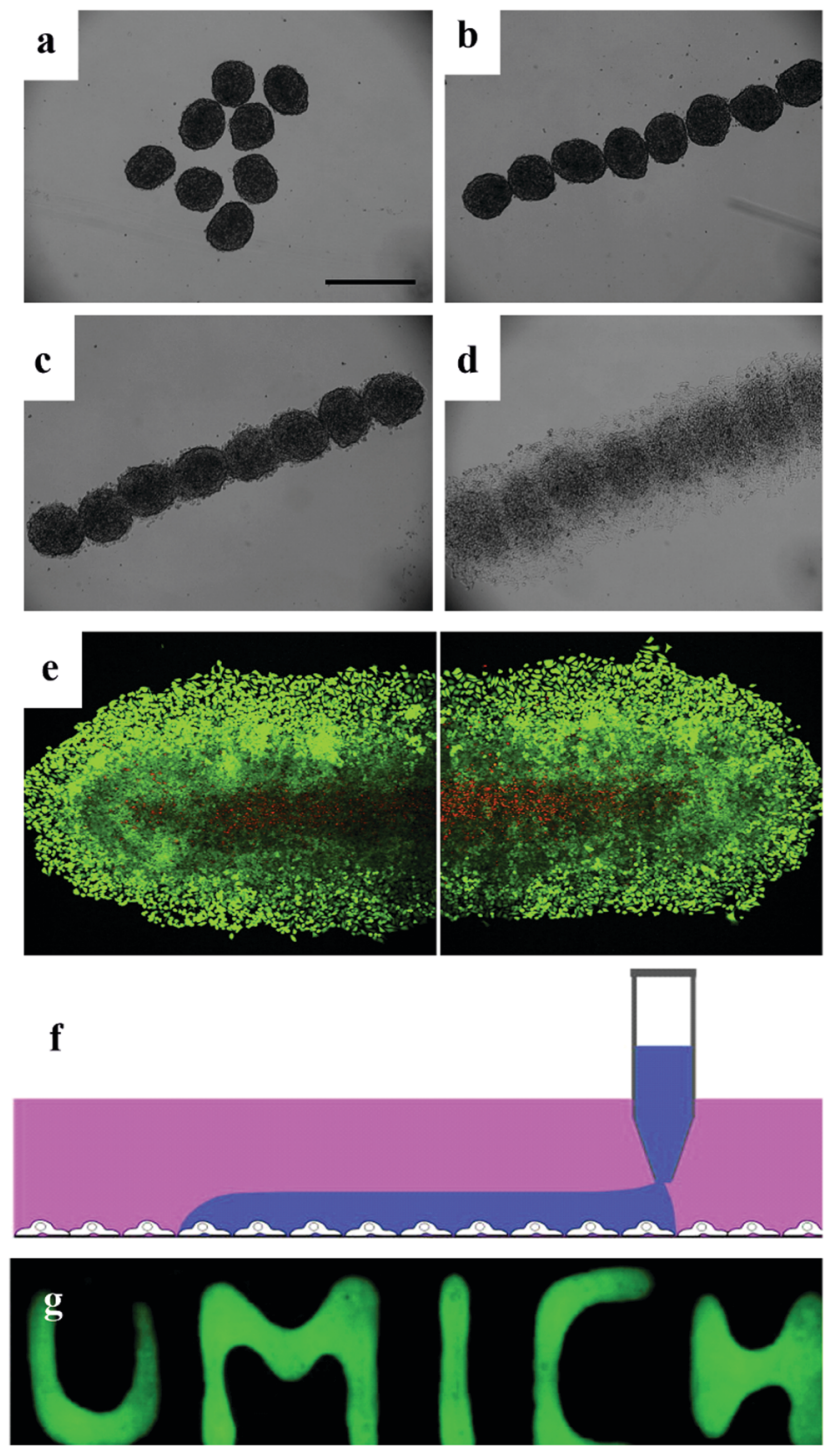

Fig. 7 Magnetic patterning of HeLa multicellular spheroids. (a) Random distribution of magnetic HeLa spheroids without any applied magnetic field. 3 day-old spheroids were used. Scale bar represents $500 \mu \mathrm{m}$. (b) Magnetic HeLa spheroids were patterned with an applied magnetic field within a few seconds. (c) Patterned magnetic HeLa spheroids start to fuse after 3 h. (d) Fusion and growth of the patterned magnetic HeLa spheroids after $18 \mathrm{~h}$. (e) Live/dead stain of the fused tissue formed by the patterned magnetic HeLa spheroids after $48 \mathrm{~h}$ of culture. Viable cells are green, while non-viable cells are red. Scale bar represents $250 \mathrm{~mm}^{32}$ Reprinted with permission from ref. 32. Copyright 2010 Elsevier. (f) Schematics of cell printing on a cell monolayer in user-defined shapes. Cell suspension in the DEX phase is printed onto an existing cell layer by continuous dispensing from the pipette tip. (g) Fluorescence images of patterned DEX phase on HEK293H cells spelling "UMICH". ${ }^{58}$ Reprinted with permission from ref. 58. Copyright 2019 Springer Nature.

Spheroid transplants have been utilized in almost all human systems including the cardiovascular system, ${ }^{90}$ digestive system, ${ }^{91}$ musculoskeletal system, ${ }^{92}$ and skin. ${ }^{63,93}$ However, spheroid implantation remains a relatively undiscovered field with limited in vivo published result. Thus, there is unexplored potential for the in vivo applications of spheroids. 


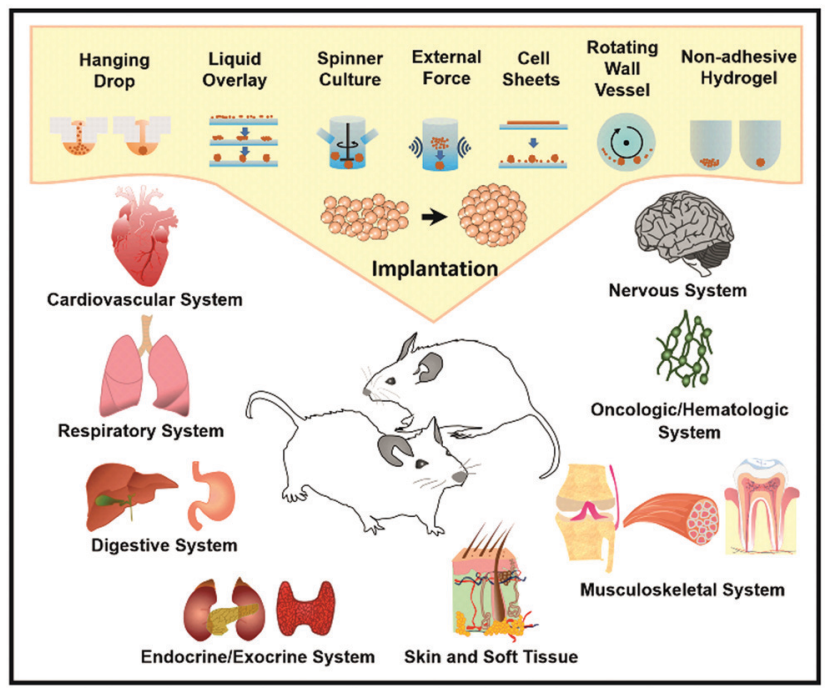

Fig. 8 In vitro therapeutic applications of cell spheroids: spheroid formation methods and organ systems for potential clinical applications. ${ }^{94}$ Reprinted with permission from ref. 94. Copyright 2018 Elsevier.

\subsection{Delivery vehicles}

Among the studies attempting to extend the limited use of cell spheroids, applying spheroids as a delivery vehicle is a novel use. Mesenchymal stem cells (MSC) are widely known their tumour-homing capability. In the use of MCS therapy, only a small number of cells and drugs are used in targeting tumours. A hybrid spheroid/nanomedicine system comprising MSC spheroids entrapping a drug-loaded nanocomposite to address these limitations was reported (Fig. 9). ${ }^{95}$ Generating MSC cells in spheroids firstly increase their tumour targeting ability and boost the payload of anticancer drugs.

This system acts as an active drug delivery platform, seeking and specifically targeting glioblastoma cells, which enables the effective delivery of chemotherapeutic drugs.
MSC hybrid nanoparticles were fabricated using microfluidic devices. This novel approach of using spheroids provides a new technique. Spheroid-loaded drugs as a "cruise missile" will be a possible application in the future. Beside this also indicates a possible way for testing the penetration of therapeutics from the core of spheroids.

\subsection{Biosensors}

The increasing attraction that $3 \mathrm{D}$ cell culture systems have been getting results in more problems in how to use in vivo-like spheroids as a model for biomedical toxicological test with simplicity. The unique architecture of spheroids is also a hinderance for drug penetration and antibody action. The challenge with the development of in vitro sensors for toxicological tests is the transformation of different signals into corresponding valid values. Recently, a biosensor was developed based on the electrochemical monitoring of the enzymatic activity of non-specific esterases of viable cells. The enzymatic activity could be easily converted to the viability of the spheroids. ${ }^{96}$ Based on this enzyme-based biosensor, it is convenient to measure the viability of both $2 \mathrm{D}$ and $3 \mathrm{D}$ cell culture formats and provide more dynamic data for drug/toxicity screening. Another type of biosensor works through collecting measurable analytical signals. The collected signals correspond to molecular recognition events occurring at the cellular and molecular levels inside the spheroids. ${ }^{97,98}$

Michelini and co-workers developed an attractive biosensor consisting of immobilized spheroids of human cell lines. Under the regulation of the NFאB pathway and a constitutive promoter, the spheroid could produce red- and green lightemitting luciferase, respectively. This dual-signal channel could enable the researchers to assess the actual toxicity and inflammatory effects of a sample, rather than identifying single constituents simultaneously. ${ }^{99}$

In addition to the usual enzymes and chemical signals, the mechanical properties of spheroids are also worth studying in $\mathbf{a}$
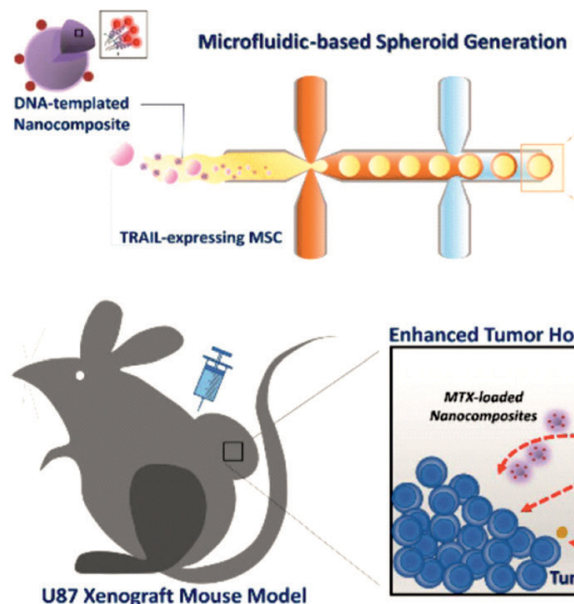

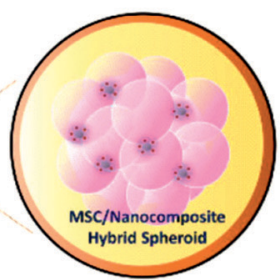

Enhanced Tumor Homing \& Retention

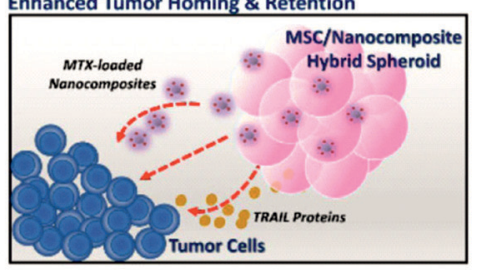

b
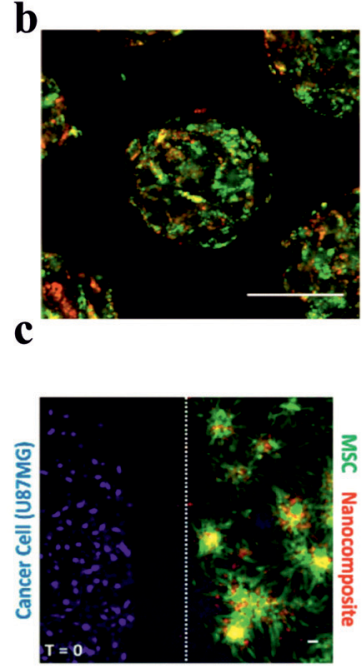
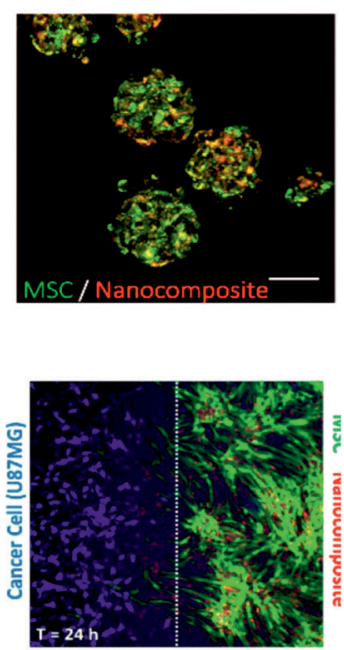

Fig. 9 Design and properties of MSC/DNA-templated nanocomposite hybrid spheroid for GBM therapy. (a) Schematic illustration of the hybrid spheroid system. (b) Representative confocal images of the hybrid spheroids. (C) In vitro tumour targeting of the hybrid spheroids. Scale bar $=50 \mu \mathrm{m} .{ }^{96}$ Reprinted with permission from ref. 96. Copyright 2019 American Chemical Society. 
future works. There has been relevant works focusing on the stiffness of spheroids with robustness.

\section{Future development of spheroid-based techniques}

The increasing biomedical application of spheroids also presents challenges. To date, $2 \mathrm{D}$ cell cultures are still the dominant cell culture model for drug testing and tissue engineering in biomedical studies. Also, several challenges restrict the industrial application of spheroids. Firstly, the fabrication of spheroids must be cost-effective, lab-friendly and high-throughput. The difficulty in achieving uniform-size spheroids is another bottleneck because size is a key feature that affects the diffusion of oxygen and nutrients inside spheroids and the internal organization of proliferative and necrotic cells. ${ }^{123}$ Finally, although there have been years of pre-clinical research, a standard inspection, analytical and imaging protocol has not been developed. Advanced imaging and analysis tools for spheroids studies are urgently necessary.

\section{Conclusions}

With the development of MCS culture techniques, in vitro models can simulate in vivo characteristics to different degrees. The formation mechanism of MCS allows researchers to gain better sight into the cell-cell and cell-matrix interactions. In addition, MCS simulation of the microenvironment in vitro enables basic research into cancer biology and tissue development, and provides opportunities for pharmacological research and the in vitro culture of $3 \mathrm{D}$ functional tissues. However, this attractive concept has many challenges. Firstly, the formation of spheroids requires a higher initial cell density since the cells number in the MCS structure limits the further expansion of spheroids. Secondly, the repeatability and quality assurance of traditional methods are low. Thirdly, the microenvironment and macro-environment of MCS in existing methods are still different from that in the in vivo environment, leading to different cellular behaviours. Current methods cannot achieve cell migration between MCS. In some mono-spheroid culture systems, there is a lack of heterogeneous cell-cell interactions, cell-ECM tissues and cellular signalling pathways. Therefore, the correlation between in vivo cells and MCS should be fully demonstrated through the analysis of RNA/DNA expression profile, protein content, and enzyme content. In addition, low yield also greatly hinders the study of MCS. Methods for the fabrication of MCS in vitro have been significantly developed in the past decade. The integration of the ATPS is considered to be a promising new approach since it not only can produce controlled uniform-size MCS, but also restore the complex cell-matrix/cell-cell interactions, which are vital for the morphology and functionality of MCSs. The physical stress existing in the ATPS can mimic the in vivo microenvironment and facilitate MCSs in developing their extracellular matrices, which are crucial for cell functions. The chambers or droplets from the ATPS allow the fabrication of MCS in a confined space to develop controllable uniform-sized MCS. Ultimately, the higher yields of ATPS can allow researchers to use the microsphere model in a wider range of applications, such as tissue engineering and toxicological tests. This method can alter the microenvironment easily, adjusting the osmotic pressure for MCS formation and growth to mimic the in vivo conditions. Moreover, the breakthrough in the size and yield control by advancements in the reviewed techniques such as ATPS and magnetic levitation create new room for the in vitro application of MCS, which will be crucial for regenerative medicine and other clinical applications, ensuring that this exciting area of research remains relevant for patient care. More elegant designs for spheroid culture systems such as co-culture/tri-culture MCS formation are needed to create physiologically relevant microand macro-environments to address the above challenges in the formation of MCS.

\section{Conflicts of interest}

There are no conflicts to declare.

\section{Acknowledgements}

A. W. thanks the Chinese Scholarship Council for the financial support of his PhD studies.

\section{References}

1 L. G. Griffith and M. A. Swartz, Nat. Rev. Mol. Cell Biol., 2006, 7, 211-224.

2 A. Abbott, Nature, 2003, 424, 870-872.

3 K. L. Schmeichel and M. J. Bissell, J. Cell Sci., 2003, 116, 2377-2388.

4 M. Simian and M. J. Bissell, J. Cell Biol., 2017, 216, 31-40.

5 J. A. Kyffin, P. Sharma, J. Leedale, H. E. Colley, C. Murdoch, A. L. Harding, P. Mistry and S. D. Webb, Toxicol. In Vitro, 2019, 55, 160-172.

6 Y. C. Tung, A. Y. Hsiao, S. G. Allen, Y. S. Torisawa, M. Ho and S. Takayama, Analyst, 2011, 136, 473-478.

7 J. Fukuda, A. Khademhosseini, Y. Yeo, X. Yang, J. Yeh, G. Eng, J. Blumling, C. F. Wang, D. S. Kohane and R. Langer, Biomaterials, 2006, 27, 5259-5267.

8 N. E. Timmins, S. Dietmair and L. K. Nielsen, Angiogenesis, 2004, 97-103.

9 N. I. Moldovan, N. Hibino and K. Nakayama, Tissue Eng., Part B, 2017, 23, 237-244.

10 R. Z. Lin and H. Y. Chang, Biotechnol. J., 2008, 3, 1172-1184. 11 T. M. Achilli, J. Meyer and J. R. Morgan, Expert Opin. Biol. Ther., 2012, 12, 1347-1360.

12 X. Cui, Y. Hartanto and H. Zhang, J. R. Soc., Interface, 2017, 14, 1-15.

13 A. Y. Hsiao, Y. C. Tung, X. Qu, L. R. Patel, K. J. Pienta and S. Takayama, Biotechnol. Bioeng., 2012, 109, 1293-1304.

14 Y. Wang and J. Wang, Analyst, 2014, 139, 2449-2458.

15 R. Foty, J. Visualized Exp., 2011, 51, 2720. 
16 O. Frey, P. M. Misun, D. A. Fluri, J. G. Hengstler and A. Hierlemann, Nat. Commun., 2014, 5(4250), 1-11.

17 K. M. Burleson, R. C. Casey, K. M. Skubitz, S. E. Pambuccian, T. R. Oegema, Jr. and A. P. Skubitz, Gynecol. Oncol., 2004, 93, 170-181.

18 Y. Sakai and K. Nakazawa, Acta Biomater., 2007, 3, 1033-1040.

19 A. N. Mehesz, J. Brown, Z. Hajdu, W. Beaver, J. V. da Silva, R. P. Visconti, R. R. Markwald and V. Mironov, Biofabrication, 2011, 3, 025002.

20 V. Beachley, V. Kasyanov, A. Nagy-Mehesz, R. Norris, I. Ozolanta, M. Kalejs, P. Stradins, L. Baptista, K. da Silva, J. Grainjero, X. Wen and V. Mironov, J. Tissue Eng., 2014, 5, 1-11.

21 E. C. Costa, D. de Melo-Diogo, A. F. Moreira, M. P. Carvalho and I. J. Correia, Biotechnol. J., 2018, 13, 1-13.

22 M. M. Capeling, M. Czerwinski, S. Huang, Y. H. Tsai, A. Wu, M. S. Nagy, B. Juliar, N. Sundaram, Y. Song, W. M. Han, S. Takayama, E. Alsberg, A. J. Garcia, M. Helmrath, A. J. Putnam and J. R. Spence, Stem Cell Rep., 2019, 12, 381-394.

23 H. Ota, R. Yamamoto, K. Deguchi, Y. Tanaka, Y. Kazoe, Y. Sato and N. Miki, Sens. Actuators, B, 2010, 147, 359-365.

24 T. G. Hammond and J. M. Hammond, Am. J. Physiol. Renal. Physiol., 2001, 281, F12-F25.

25 M. Krüger, S. Kopp, M. Wehland, J. Bauer, S. Baatout, M. Moreels, M. Egli, T. J. Corydon, M. Infanger and D. Grimm, Acta Astronaut., 2019, 159, 267-272.

26 T. T. Chang and M. Hughes-Fulford, Am. J. Physiol. Renal. Physiol., 2009, 15, 559-567.

27 H. F. Chan, Y. Zhang and K. W. Leong, Small, 2016, 12, 2720-2730.

28 K. Ziolkowska, A. Stelmachowska, R. Kwapiszewski, M. Chudy, A. Dybko and Z. Brzozka, Biosens. Bioelectron., 2013, 40, 68-74.

29 L. Y. Wu, D. Di Carlo and L. P. Lee, Biomed. Microdevices, 2008, 10, 197-202.

30 H. Ota and N. Miki, Sens. Actuators, A, 2011, 169, 266-273.

31 G. R. Souza, J. R. Molina, R. M. Raphael, M. G. Ozawa, D. J. Stark, C. S. Levin, L. F. Bronk, J. S. Ananta, J. Mandelin, M. M. Georgescu, J. A. Bankson, J. G. Gelovani, T. C. Killian, W. Arap and R. Pasqualini, Nat. Nanotechnol., 2010, 5, 291-296.

32 V. H. Ho, K. H. Muller, A. Barcza, R. Chen and N. K. Slater, Biomaterials, 2010, 31, 3095-3102.

33 R. Z. Lin, W. C. Chu, C. C. Chiang, C. H. Lai and H. Y. Chang, Tissue Eng., Part C, 2008, 14, 197-205.

34 N. S. Lewis, E. E. Lewis, M. Mullin, H. Wheadon, M. J. Dalby and C. C. Berry, J. Tissue Eng., 2017, 8, 2041731417704428.

35 J. A. Kim, J. H. Choi, M. Kim, W. J. Rhee, B. Son, H. K. Jung and T. H. Park, Biomaterials, 2013, 34, 8555-8563.

36 S. Lemmo, E. Atefi, G. D. Luker and H. Tavana, Cell. Mol. Bioeng., 2014, 7, 344-354.

37 S. Singh and H. Tavana, Front. Chem., 2018, 6, 379.

38 B. P. Binks and H. Shi, Langmuir, 2019, 35, 4046-4057.

39 B. T. Nguyen, T. Nicolai and L. Benyahia, Langmuir, 2013, 29, 10658-10664.

40 H. Shin, C. Han, J. M. Labuz, J. Kim, J. Kim, S. Cho, Y. S. Gho, S. Takayama and J. Park, Sci. Rep., 2015, 5, 13103.
41 H. Sakuta, T. Fujimoto, Y. Yamana, Y. Hoda, K. Tsumoto and K. Yoshikawa, Front. Chem., 2019, 7, 44.

42 J. Benavides, O. Aguilar, B. H. Lapizco-Encinas and M. RitoPalomares, Chem. Eng. Technol., 2008, 31, 838-845.

43 V. Ramakrishnan, L. C. Goveas, N. Suralikerimath, C. Jampani, P. M. Halami and B. Narayan, Biocatal. Agric. Biotechnol., 2016, 6, 19-27.

44 E. Atefi, R. Joshi, J. A. Mann, Jr. and H. Tavana, ACS Appl. Mater. Interfaces, 2015, 7, 21305-21314.

45 S. P. M. Ventura, R. L. F. de Barros, J. M. de Pinho Barbosa, C. M. F. Soares, Á. S. Lima and J. A. P. Coutinho, Green Chem., 2012, 14, 734-740.

46 M. Rito-Palomares, J. Chromatogr. B: Anal. Technol. Biomed. Life Sci., 2004, 807, 3-11.

47 J. M. Cabral, Adv. Biochem. Eng./Biotechnol., 2007, 106, 151-171. 48 B. U. Moon, D. K. Hwang and S. S. Tsai, Lab Chip, 2016, 16, 2601-2608.

49 S. Álvaro, G. Marín, S. Vincent, Á. G. Marín, W. V. Hoeve, P. García-sánchez, N. Convine, A. Rosser-james, M. Tyler, K. Bandoo, L. Warncke, A. Lee and V. Vogel, Lab Chip, 2013, 15, 4491-4498.

50 Y. Liu, N. O. Nambu and M. Taya, Biomed. Microdevices, 2017, 19, 55.

51 D. Lee and C. Cha, Pharmaceutics, 2018, 10, 229.

52 J. A. De Lora, F. A. Fencl, A. D. Y. Macias Gonzalez, A. Bandegi, R. Foudazi, G. P. Lopez, A. P. Shreve and N. J. Carroll, ACS Appl. Bio Mater., 2019, 2, 4097-4105.

53 S. L. Ham, E. Atefi, D. Fyffe and H. Tavana, J. Visualized Exp., 2015, 98, 754.

54 K. Zhu, Y. Yu, Y. Cheng, C. Tian, G. Zhao and Y. Zhao, ACS Appl. Mater. Interfaces, 2019, 11, 4826-4832.

55 C. Han, S. Takayama and J. Park, Sci. Rep., 2015, 5, 11891.

56 E. Atefi, S. Lemmo, D. Fyffe, G. D. Luker and H. Tavana, Adv. Funct. Mater., 2014, 24, 6509-6515.

57 S. L. Ham, R. Joshi, G. D. Luker and H. Tavana, Adv. Healthcare Mater., 2016, 5, 2788-2798.

58 H. Tavana, A. Jovic, B. Mosadegh, Q. Y. Lee, X. Liu, K. E. Luker, G. D. Luker, S. J. Weiss and S. Takayama, Nat. Mater., 2009, 8, 736-741.

59 G. Balakrishnan, T. Nicolai, L. Benyahia and D. Durand, Langmuir, 2012, 28, 5921-5926.

60 L.-H. Xue, C.-Y. Xie, S.-X. Meng, R.-X. Bai, X. Yang, Y. Wang, S. Wang, B. P. Binks, T. Guo and T. Meng, ACS Macro Lett., 2017, 6, 679-683.

61 P. Singh, B. Medronho, M. G. Miguel and J. Esquena, Food Hydrocolloids, 2018, 75, 41-50.

62 A. A. K. Das, B. W. Filby, D. A. Geddes, D. Legrande and V. N. Paunov, Mater. Horiz., 2017, 4, 1196-1200.

63 S. B. G. Celik, S. R. Dominici, B. W. Filby, A. A. K. Das, L. A. Madden and V. N. Paunov, Biomimetics, 2019, 4, 50 .

64 H. F. Lu, K. N. Chua, P. C. Zhang, W. S. Lim, S. Ramakrishna, K. W. Leong and H. Q. Mao, Acta Biomater., 2005, 1, 399-410.

65 A. Y. Hsiao, Y. S. Torisawa, Y. C. Tung, S. Sud, R. S. Taichman, K. J. Pienta and S. Takayama, Biomaterials, 2009, 30, 3020-3027. 
66 X. Yang, X. Wang, X. Huang, R. Hang, X. Zhang and B. Tang, J. Mater. Sci.: Mater. Med., 2017, 28, 139.

67 J. Liu, L. A. Kuznetsova, G. O. Edwards, J. Xu, M. Ma, W. M. Purcell, S. K. Jackson and W. T. Coakley, J. Cell. Biochem., 2007, 102, 1180-1189.

68 K. Ohashi, T. Yokoyama, M. Yamato, H. Kuge, H. Kanehiro, M. Tsutsumi, T. Amanuma, H. Iwata, J. Yang, T. Okano and Y. Nakajima, Nat. Med., 2007, 13, 880-885.

69 S. C. Ramaiahgari, M. W. den Braver, B. Herpers, V. Terpstra, J. N. Commandeur, B. van de Water and L. S. Price, Arch. Toxicol., 2014, 88, 1083-1095.

70 A. C. Y. Chua, A. Ananthanarayanan, J. J. Y. Ong, J. Y. Wong, A. Yip, N. H. Singh, Y. Qu, L. Dembele, M. McMillian, R. Ubalee, S. Davidson, A. Tungtaeng, R. Imerbsin, K. Gupta, C. Andolina, F. Lee, S. W. T. K, F. Nosten, B. Russell, A. Lange, T. T. Diagana, L. Renia, B. K. S. Yeung, H. Yu and P. Bifani, Biomaterials, 2019, 216, 119221.

71 J. Gu, X. Shi, Y. Zhang, X. Chu, H. Hang and Y. Ding, Hepatol. Res., 2009, 39, 398-407.

72 A. M. Laib, A. Bartol, A. Alajati, T. Korff, H. Weber and H. G. Augustin, Nat. Protoc., 2009, 4, 1202-1215.

73 G. Mehta, A. Y. Hsiao, M. Ingram, G. D. Luker and S. Takayama, J. Controlled Release, 2012, 164, 192-204.

74 T. Rodrigues, B. Kundu, J. Silva-Correia, S. C. Kundu, J. M. Oliveira, R. L. Reis and V. M. Correlo, Pharmacol. Ther., 2018, 184, 201-211.

75 M. Upreti, A. Jamshidi-Parsian, N. A. Koonce, J. S. Webber, S. K. Sharma, A. A. Asea, M. J. Mader and R. J. Griffin, Transl. Oncol., 2011, 4, 365-376.

76 J. Debnath and J. S. Brugge, Nat. Rev. Cancer, 2005, 5, 675-688.

77 G. M. Thurber, M. M. Schmidt and K. D. Wittrup, Adv. Drug Delivery Rev., 2008, 60, 1421-1434.

78 X. Ma, X. Qu, W. Zhu, Y. S. Li, S. Yuan, H. Zhang, J. Liu, P. Wang, C. S. Lai, F. Zanella, G. S. Feng, F. Sheikh, S. Chien and S. Chen, Proc. Natl. Acad. Sci. U. S. A., 2016, 113, 2206-2211.

79 G. Lazzari, V. Nicolas, M. Matsusaki, M. Akashi, P. Couvreur and S. Mura, Acta Biomater., 2018, 78, 296-307.

80 T. R. Olsen, B. Mattix, M. Casco, A. Herbst, C. Williams, A. Tarasidis, D. Simionescu, R. P. Visconti and F. Alexis, Acta Biomater., 2015, 13, 188-198.

81 A. C. Daquinag, G. R. Souza and M. G. Kolonin, Tissue Eng., Part C, 2013, 19, 336-344.

82 A. Alajati, A. M. Laib, H. Weber, A. M. Boos, A. Bartol, K. Ikenberg, T. Korff, H. Zentgraf, C. Obodozie, R. Graeser, S. Christian, G. Finkenzeller, G. B. Stark, M. Heroult and H. G. Augustin, Nat. Methods, 2008, 5, 439-445.

83 A. A. Chen, D. K. Thomas, L. L. Ong, R. E. Schwartz, T. R. Golub and S. N. Bhatia, Proc. Natl. Acad. Sci. U. S. A., 2011, 108, 11842-11847.

84 A. P. Rago, D. M. Dean and J. R. Morgan, Biotechnol. Bioeng., 2009, 102, 1231-1241.

85 B. M. Mattix, T. R. Olsen, M. Casco, L. Reese, J. T. Poole, J. Zhang, R. P. Visconti, A. Simionescu, D. T. Simionescu and F. Alexis, Biomaterials, 2014, 35, 949-960.
86 M. W. Laschke and M. D. Menger, Trends Biotechnol., 2017, 35, 133-144.

87 R. F. Fakhrullin, A. I. Zamaleeva, R. T. Minullina, S. A. Konnova and V. N. Paunov, Chem. Soc. Rev., 2012, 41, 4189-4206.

88 R. Agarwal, K. R. Ko, P. F. Gratzer and J. P. Frampton, MRS Adv., 2017, 2, 2443-2449.

89 J. Gopinathan and I. Noh, Biomater. Res., 2018, 22, 11.

90 R. Noguchi, K. Nakayama, M. Itoh, K. Kamohara, K. Furukawa, J. I. Oyama, K. Node and S. Morita, J. Heart Lung Transplant., 2016, 35, 137-145.

91 J. Bierwolf, T. Volz, M. Lutgehetmann, L. Allweiss, K. Riecken, M. Warlich, B. Fehse, J. C. Kalff, M. Dandri and J. M. Pollok, Tissue Eng., Part A, 2016, 22, 742-753.

92 Y. Yamaguchi, J. Ohno, A. Sato, H. Kido and T. Fukushima, BMC Biotechnol., 2014, 14, 105.

93 N. Lebonvallet, N. Boulais, C. Le Gall, U. Pereira, D. Gauche, E. Gobin, J. O. Pers, C. Jeanmaire, L. Danoux, G. Pauly and L. Misery, Exp. Dermatol., 2012, 21, 156-158.

94 C. S. Ong, X. Zhou, J. Han, C. Y. Huang, A. Nashed, S. Khatri, G. Mattson, T. Fukunishi, H. Zhang and N. Hibino, Biotechnol. Adv., 2018, 36, 494-505.

95 S. Suryaprakash, Y. H. Lao, H. Y. Cho, M. Li, H. Y. Ji, D. Shao, H. Hu, C. H. Quek, D. Huang, R. L. Mintz, J. R. Bago, S. D. Hingtgen, K. B. Lee and K. W. Leong, Nano Lett., 2019, 19, 1701-1705.

96 E. Flampouri, S. Imar, K. OConnell and B. Singh, ACS Sens., 2019, 4, 660-669.

97 W. He, S. Yuan, W. H. Zhong, M. A. Siddikee and C. C. Dai, Appl. Microbiol. Biotechnol., 2016, 100, 1109-1119.

98 G. Thouand, Anal. Bioanal. Chem., 2018, 410, 1189-1190.

99 E. Michelini, M. M. Calabretta, L. Cevenini, A. Lopreside, T. Southworth, D. M. Fontaine, P. Simoni, B. R. Branchini and A. Roda, Biosens. Bioelectron., 2019, 123, 269-277.

100 R. F.-X. Tomasi, S. Sart, T. Champetier and C. N. Baroud, Cell Rep., 2020, 31, 107670.

101 D. A. Cristaldi, A. Sargenti, S. Bonetti, F. Musmeci, C. Delprete, F. Bacchi, S. Pasqua, C. Cavallo, L. Bonsi, F. Alviano, D. Gazzola and S. Santi, Micromachines, 2020, 11, 465.

102 M. Vinken, T. Vanhaecke, P. Papeleu, S. Snykers, T. Henkens and V. Rogiers, Cell. Signalling, 2006, 18, 592-600.

103 J. C. Hervé and M. Derangeon, Cell Tissue Res., 2013, 352, 21-31.

104 F. Liu, G. Tan, J. Li, X. Dong, G. W. Krissansen and X. Sun, Cancer Sci., 2007, 98, 1381-1387.

105 E. Fennema, N. Rivron, J. Rouwkema, C. van Blitterswijk and J. De Boer, Trends Biotechnol., 2013, 31, 108-115.

106 Y. L. Huang, Y. Ma, C. Wu, C. Shiau, J. E. Segall and M. Wu, Sci. Rep., 2020, 10, 9648.

107 T. Okuyama, H. Yamazoe, N. Mochizuki, A. Khademhosseini, H. Suzuki and J. Fukuda, J. Biosci. Bioeng., 2010, 110, 572-576.

108 L. Yu, M. C. Chen and K. C. Cheung, Lab Chip, 2010, 10, 2424-2432.

109 A. G. Teixeira, R. Agarwal, K. R. Ko, J. Grant-Burt, B. M. Leung and J. P. Frampton, Adv. Healthcare Mater., 2018, 7.

110 J. F. B. Pereira, M. G. Freire and J. A. P. Coutinho, Fluid Phase Equilib., 2020, 505, 112341. 
111 P. Shahi Thakuri, S. L. Ham, G. D. Luker and H. Tavana, Mol. Pharmaceutics, 2016, 13, 3724-3735.

112 L. Yu, M. C. Chen and K. C. Cheung, Lab Chip, 2010, 10, 2424-2432.

113 C. Moraes, A. B. Simon, A. J. Putnam and S. Takayama, Biomaterials, 2013, 34, 9623-9631.

114 M. Iqbal, Y. Tao, S. Xie, Y. Zhu, D. Chen, X. Wang, L. Huang, D. Peng, A. Sattar, M. A. B. Shabbir, H. I. Hussain, S. Ahmed and Z. Yuan, Biol. Proced. Online, 2016, 18, 18.

115 C. Pauli, B. D. Hopkins, D. Prandi, R. Shaw, T. Fedrizzi, A. Sboner, V. Sailer, M. Augello, L. Puca, R. Rosati, T. J. McNary, Y. Churakova, C. Cheung, J. Triscott, D. Pisapia, R. Rao, J. M. Mosquera, B. Robinson, B. M. Faltas, B. E. Emerling, V. K. Gadi, B. Bernard, O. Elemento, H. Beltran, F. Demichelis, C. J. Kemp, C. Grandori, L. C. Cantley and M. A. Rubin, Cancer Discovery, 2017, 7, 462-477.

116 F. Weeber, S. N. Ooft, K. K. Dijkstra and E. E. Voest, Cell Chem. Biol., 2017, 24, 1092-1100.
117 A. S. Nunes, A. S. Barros, E. C. Costa, A. F. Moreira and I. J. Correia, Biotechnol. Bioeng., 2019, 116, 206-226.

118 G. S. Kronemberger, R. A. M. Matsui, G. Miranda, J. M. Granjeiro and L. S. Baptista, World J. Stem Cells, 2020, 12, 110-122.

119 D. N. Heo, M. Hospodiuk and I. T. Ozbolat, Acta Biomater., 2019, 95, 348-356.

120 G. S. Kronemberger, G. M. L. Dalmonico, A. L. Rossi, P. E. C. Leite, A. M. Saraiva, A. Beatrici, K. R. Silva, J. M. Granjeiro and L. S. Baptista, Artif. Organs, 2020, 44, E288-E299.

121 C. Hoefner, C. Muhr, H. Horder, M. Wiesner, K. Wittmann, D. Lukaszyk, K. Radeloff, M. Winnefeld, M. Becker, T. Blunk and P. Bauer-Kreisel, Tissue Eng., Part A, 2020, 26, 915-926.

122 T. Ahmad, H. Byun, J. Lee, S. K. Madhurakat Perikamana, Y. M. Shin, E. M. Kim and H. Shin, Biomaterials, 2020, 230, 119652.

123 W. Asghar, R. El Assal, H. Shafiee, S. Pitteri, R. Paulmurugan and U. Demirci, Mater. Today, 2015, 18, 539-553. 